\title{
Análisis comparativo de la Zona Franca de Manaos y el área aduanera especial de Tierra del Fuego *
}

\author{
Marta Bekerman \\ Federico Dulcich ${ }^{* * *}$
}

\begin{abstract}
Resumen
Los objetivos para la creación de la Zona Franca de Manaos (ZFM) y del Área Aduanera Especial de Tierra del Fuego (TDF) han sido similares, pero sus trayectorias han sido divergentes. Los primigenios objetivos de poblar las regiones dieron paso al incentivo a sectores estratégicos vinculados a la industrialización y la sustitución de importaciones. Luego de analizar la normativa y el desempeño económico de ambas regiones en la última década, las principales diferencias se encuentran en la mayor integración (local y con su territorio nacional) que presenta la ZFM; así como un sendero de inversiones menos errático, y una estructura productiva más diversificada. Estas divergencias encuentran explicación en diferencias en la regulación de las zonas. Concluyendo, se plantea la complejidad (e incluso la posible inconsistencia) de atacar objetivos de desarrollo local y sectores estratégicos simultáneamente.
\end{abstract}

Palabras-clave: Desarrollo local; Sectores estratégicos; Política económica; Manaos; Tierra del Fuego.

\section{Abstract \\ Comparative analysis of the Manaus Free Trade Zone and special customs area of Tierra del Fuego}

The objectives for the creation of the Manaus Free Zone (ZFM) and the Special Customs Area of Tierra del Fuego (TDF) were similar, however their paths have diverged. The original objectives of populating the regions gave way to providing incentive to strategic sectors linked to industrialization and import substitution. After analyzing the regulations and economic performance of both regions in the last decade, the main differences are in the greater integration (both local and with the national territory) that the ZFM presents; the less erratic path of investment and the more diversified production structure of this zone. These differences are explained by the differences in the zone`s regulation. In conclusion, the complexity (and even the possible inconsistency) of simultaneously attacking local development objectives and strategic sectors development arises.

Keywords: Local development; Strategic sectors; Economic policy; Manaus; Tierra del Fuego. JEL R11, L60, L52, D61.

\section{Introducción}

En el marco de la estrategia de crecimiento basada en la sustitución de importaciones, Argentina y Brasil desarrollaron durante las décadas del sesenta y

* Artigo recebido em 30 de junho de 2015 e aprovado em 28 de junho de 2017.

** Directora del Centro de Estudios de la Estructura Económica (CENES) de la Facultad de Ciencias Económicas de la Universidad de Buenos Aires, e Investigadora Principal del Consejo Nacional de Investigaciones Científicas y Técnicas (Conicet), Buenos Aires, Argentina. E-mail: marbekerman@gmail.com.

*** Investigador del Cenes de la Facultad de Ciencias Económicas de la Universidad de Buenos Aires, y becario de investigación del Conicet, Buenos Aires, Argentina. E-mail: federicomd2001@gmail.com. 
setenta un conjunto de instrumentos de promoción e incentivo para el desarrollo económico local de distintas zonas al interior de dichos países. La creación del Área Aduanera Especial de Tierra del Fuego (TDF) en la Argentina y de la Zona Franca de Manaos (ZFM) en Brasil tiene lugar en este particular contexto.

La principal justificación para la creación del área especial de TDF es de tipo "geopolítico"; mientras que la ZFM combina dichos objetivos con los de integración social y de disminuir la desigualdad regional. La existencia de grandes distancias de los centros de consumo y escasa población, llevaron a la aplicación de importantes medidas de promoción fiscales y aduaneras tendientes a facilitar la producción como incentivo para la radicación de empresas industriales en dichas regiones.

Es importante destacar la importancia de estas experiencias de desarrollo local y de política productiva en general, especialmente considerando que ambos regímenes acaparan parte importante del gasto de promoción industrial de cada país. Asimismo, se tornan relevantes ante las escasas políticas exitosas de desarrollo local existentes en ambos países y la significativa desigualdad regional de ingresos que predomina en sus territorios. Por ende, la principal motivación de este trabajo es estudiar estas experiencias para extraer lecciones que aporten a los debates de reconfiguración de éstas u otras experiencias de desarrollo local.

Bajo esta motivación, el objetivo del presente trabajo es analizar y comparar la evolución económica de ambas regiones en el período 2003-2013, así como la regulación que sustenta dichos regímenes especiales. En el marco teórico de las políticas productivas en general (fallas de mercado, políticas óptimas, sectores estratégicos, etc.) y del Desarrollo Económico Local en particular, el objetivo es constatar la existencia de consistencia entre los objetivos y los instrumentos de política utilizados, hacer consideraciones sobre la eficiencia de los regímenes para lograr dichos objetivos, y abrir el debate sobre la concepción que los sustenta.

Como hipótesis, se plantea la posible inconsistencia entre los objetivos de transformación estructural a partir de la industrialización y los de desarrollo local, considerando que dicha localización puede no ser la mejor para los sectores industriales promovidos. Esto es así especialmente para el caso de TDF, donde existen oportunidades para explorar una mayor expansión de la producción y el empleo en otros sectores. Esta inconsistencia entre objetivos genera problemas en términos de la eficiencia de los regímenes bajo análisis, sustentados tanto en sus objetivos como en los instrumentos utilizados en una visión basada exclusivamente en la industrialización por sustitución de importaciones; con escasas consideraciones (especialmente en TDF) sobre procesos de aprendizaje y desarrollo tecnológico, clusters, marco institucional de los regímenes, entre otros.

El presente trabajo se estructura de la siguiente forma: en la sección 1 presentaremos el concepto de desarrollo económico local, que nos dará el marco 
teórico para analizar tanto la regulación como la evolución económica de ambas regiones. Posteriormente, en la sección 2 se analizarán los marcos regulatorios de la ZFM y de TDF, a fin de estudiar y comparar los principales beneficios (fiscales, comerciales, etc.) otorgados en ambas regiones. En la sección 3 se realiza un estudio comparado de los principales indicadores económicos de las dos zonas, fundamentalmente en lo referido a producción, empleo, comercio e inversiones. Finalmente, se presentan las conclusiones y comentarios finales.

\section{Marco teórico: políticas óptimas, externalidades, capacidades tecnológicas y marco institucional en el Desarrollo Económico Local}

Los casos del Área Aduanera Especial de TDF y de la ZFM se enmarcan en lo que se conoce en la literatura de la Ciencia Económica como problemas de Desarrollo Económico Local (Helmsing, 2001; Bartik, 2003). Desde una perspectiva del mercado como mecanismo exclusivo de asignación de recursos, las condiciones de viabilidad económica de una región están determinadas por la existencia de una ventaja absoluta en la dotación de algún factor productivo (recursos naturales, mano de obra calificada, etc.) en relación con el resto de las regiones del país, y que dicha dotación de factores clave se corresponda a nivel tecnológico con un sector donde dicha economía presenta ventajas comparativas dentro de la división internacional del trabajo (Olivera, 1970), determinando lo que se denomina eficiencia estática, sujeta a los recursos y la tecnología disponibles.

Sin embargo, pueden existir objetivos extra-económicos para desarrollar económicamente una región en particular. Como hemos visto, para los casos del Área Aduanera Especial de TDF y la ZFM el fundamento principal de las políticas económicas orientadas hacia esas regiones es de carácter geopolítico: apuntan a incentivar la producción de manera de fomentar la radicación de empresas, y que de esta forma aumente la demanda de trabajo y la población; mientras que en la ZFM priman asimismo objetivos de integración social y regional, para los cuales la literatura demuestra la existencia de soluciones muy diversas en términos productivos e institucionales (Bond, 2003), como las estrategias que se focalizan en las comunidades de bajos ingresos y sus organizaciones.

Bajo estas circunstancias, cabe preguntarse: ¿Cuáles son las mejores políticas para lograr dichos objetivos? La idea del diseño e implementación de políticas económicas requiere no solo que haya consistencia entre objetivos e instrumentos, sino también que dichos objetivos se cumplan minimizando las distorsiones derivadas de la política aplicada. Por ende, la política no solo debe ser efectiva (es decir, cumplir con los objetivos propuestos) sino asimismo ser eficiente, lo que significa que debe alcanzarlos con el menor costo posible. La literatura relativa a las políticas óptimas y de second best hace fuerte hincapié en estas 
consideraciones, con eje en la búsqueda de aquellos instrumentos que presenten los mayores niveles de optimalidad en términos de costo-beneficio (Corden, 1978).

En general, esta literatura justifica las políticas de intervención a partir de reconocer la existencia de las denominadas fallas de mercado (Bartik, 1990). Esas fallas llegan a determinar que el mercado como mecanismo de asignación de factores productivos pueda arrojar resultados subóptimos en términos de los niveles de inversión y producción, así como en su composición sectorial. Las fallas de mercado pueden abarcar diversos campos, como la información asimétrica, elevados costos de transacción, o la existencia de externalidades que no pueden ser incluidas en las funciones de beneficios de los agentes privados. Por ende, la intervención de Estado puede ser justificada para encauzar a la estructura económica hacia un equilibrio de mayor productividad e ingreso (Ros, 2000). Esto puede lograrse a través de la coordinación de los procesos de inversión privada de manera de evitar las posibles fallas de coordinación y aprovechar los rendimientos crecientes a escala; así como favoreciendo a los sectores con externalidades positivas y/o neutralizando otras fallas de mercado (Bartik, 1990; Helmsing, 2001).

Posteriormente, la teoría del Desarrollo Económico Local superó la estrecha visión de las fallas de mercado para considerar que los agentes económicos son heterogéneos en sus capacidades tecnológicas, tanto de adopción de tecnología externa y/o aprendizaje, así como en desarrollar nuevas técnicas productivas o productos. Aquí estamos ante efectos internos de la tecnología, que repercuten en la función de beneficios de las firmas, y no ya ante las externalidades que el desarrollo tecnológico puede generar.

En términos de la generación de innovaciones, cabe destacar que las actividades de investigación y desarrollo (I+D) que se llevan adelante con miras a obtener nuevos productos o técnicas productivas poseen una elevada incertidumbre en sus resultados, tanto en la esfera técnica como económica. En términos técnicos, esta incertidumbre fundamenta que sea el Estado quien financie (e incluso muchas veces ejecute) las actividades de I+D. Por otra parte, cabe destacar el carácter de "bien público" del conocimiento técnico codificado, que posee los atributos de ser no rival y sólo parcialmente excluyente mediante derechos de propiedad intelectual (DPI), como patentes, modelos industriales, derechos de autor, etc. Nuevamente, esta incapacidad de privatizar completamente dicho conocimiento genera una subinversión privada en este tipo de actividades (especialmente en el caso de conocimiento científico), que debe ser cubierta por el Estado (Mazzucato, 2011).

Por otro lado, es importante remarcar que para transformar una innovación en ganancias diferenciales es clave que la misma no se difunda, proceso que puede verse obturado principalmente de dos maneras: si el aprendizaje e imitación de dicha nueva técnica productiva o producto depende de conocimiento tácito no asequible a 
los potenciales competidores (generalmente denominados "secreto técnico"); o si existe la posibilidad de generar procesos de aprendizaje pero estas innovaciones están protegidas por DPI (Teece, 2006). De esta forma, la generación de innovaciones económicamente exitosas requiere la interacción de los componentes público y privado del Sistema Nacional de Innovación (Freeman, 1995), desde la ciencia básica hasta el nuevo producto, su comercialización y la interacción con el usuario o cliente; en un marco institucional que incentive la generación de dichas innovaciones de manera sistémica (Cimoli; Ferraz; Primi, 2009). Ante la incesante dinámica del desarrollo tecnológico y del cambio de preferencias de los consumidores, los agentes deben poseer capacidades dinámicas de desarrollo y adopción de tecnología, y de aprendizaje (Teece; Augier, 2009).

Diversos autores han profundizado esta concepción para destacar los atributos locales de los sistemas de innovación (Cooke et al., 1997; Morgan, 1997). En general, se pondera la potencialidad existente a nivel local de desarrollar aprendizajes colectivos, mediante la interacción que genera dicha proximidad; así como remarcan que los aprendizajes individuales de los trabajadores no son apropiables a nivel firma pero sí poseen externalidades cuyo efecto positivo se circunscribe al ámbito local, mientras los mismos continúen en dicho mercado laboral. Asimismo, existen economías de escala en el desarrollo de proveedores especializados (Helmsing, 2001), así como ventajas para desarrollar proyectos de $\mathrm{I}+\mathrm{D}$ conjuntos (como los procesos de open innovation en EEUU analizados por Block y Keller, 2011), entro otros.

Por otra parte, en una gran cantidad de sectores, son las firmas multinacionales (FMN), las que poseen la tecnología de frontera así como las capacidades para generar nuevas técnicas productivas y productos. Estas firmas, siguiendo sus estrategias globales, suelen coordinar las cadenas productivas a nivel internacional (Gereffi et al., 2005); dentro de las cuales se insertan los clusters locales (Helmsing, 2001). Por ende, a pesar de que algunas veces las estrategias de las FMN intentan limitar el derrame tecnológico al interior de sus cadenas productivas (Baldwin, 2011), para las empresas locales es importante la mencionada capacidad dinámica de aprendizaje tecnológico a nivel individual así como aprovechar el potencial de los aprendizajes colectivos de manera dinámica, ante los acelerados cambios técnicos y económicos que impone la internacionalización de la producción (Wolfson; Frisken, 2000). En la misma línea, Porter (2000) destaca que dicha internacionalización de la producción redujo ciertas desventajas de localización (ante la posibilidad de intercambiar información y coordinar la producción a nivel global y de manera inmediata mediante las tecnologías de la información y las comunicaciones - TICs -); pero que eso por sí solo no genera nuevas ventajas de localización, siendo que las mismas actualmente están asociadas a los procesos de aprendizaje colectivos y a la generación de innovaciones que 
desarrollan los clusters locales, dependientes de la organización industrial, el marco institucional, y la interacción público-privada, entre otras.

De esta forma, en términos de las instituciones y del gobierno (governance) del desarrollo económico local, es importante remarcar el rol y la interacción de dos actores fundamentales: el gobierno local y las asociaciones empresarias (Helmsing, 2001). Estas últimas, además de representar sus intereses particulares, pueden aportar brindando a sus asociados ciertos bienes y servicios "semi-públicos" o "bienes club" (bienes con exclusión pero con baja o nula rivalidad), como capacitación o consultorías.

Por otra parte, el gobierno local y sus instituciones han cobrado mayor relevancia en las últimas décadas, ante la descentralización de los sistemas políticos y los recursos económicos en diversos países; tanto en los países desarrollados por cuestiones presupuestarias como en los países en desarrollo y en las economías que abandonaron la planificación central (Liou, 2009). Considerando que es en las ciudades donde se concentran las actividades más dinámicas en términos tecnológicos (Wolfson; Frisken, 2000), diversos autores han ponderado a los gobiernos locales por su capacidad de identificar los recursos disponibles y las necesidades y problemas específicos de dichas regiones (Helmsing, 2001; Liou, 2009). Según Helmsing (2001), en contraposición al comportamiento de los gobiernos centrales, los gobiernos locales gastan una proporción reducida de sus presupuestos en programas de desarrollo económico local, ya que juegan más bien un rol de facilitadores y canalizadores de dicho proceso.

Sin embargo, es importante hacer una consideración complementaria, que transciende el marco teórico del Desarrollo Económico Local y ha sido abordada por la literatura económica de manera más general. El proceso de búsqueda de la eficiencia dinámica desarrollando sectores con perspectivas de mayor productividad en el largo plazo, favorecido por la implementación de las políticas verticales que pretenden "guiar al mercado" hacia dichos sectores (Wade, 1989), no debe ser obstaculizada por un posible comportamiento de rent seeking de los agentes beneficiarios de dichas políticas. Ante la carencia de competencia entre agentes privados que implican algunas políticas de protección comercial o diversos esquemas de subsidios y/o exenciones impositivas, los mismos pueden no incentivar a los agentes a llevar adelante los objetivos buscados en términos de modernización tecnológica e innovaciones, entre otros; sino solo acaparar dichos beneficios fiscales y/o comerciales meramente como ganancias diferenciales. En este caso, la política económica se vuelve no solo ineficiente (debido a que disminuye el rendimiento buscado en relación a una cierta disponibilidad presupuestaria), sino incluso inefectiva, debido a que no se alcanzan los objetivos. 
En dichos casos, ante la falta de disciplina que implica la falta de competencia del mercado, el Estado debe estructurar un marco regulatorio para efectivizar el cumplimiento de dichos objetivos, fiscalizando el cumplimiento de las distintas metas (de inversiones, adopción de tecnología, empleo, exportaciones, etc.), a la par que permita ir limitando en el tiempo el alcance de los instrumentos de estímulo. La experiencia de los tigres asiáticos y de China demuestra la importancia de este tipo de regulaciones en un marco de menor intensidad de la competencia (Stiglitz, 1997); a la par que demuestra el desafío político de retirar los incentivos a las empresas que no cumplen las metas, de manera de consolidar el enforcement de las políticas (Rodrik, 2006). Al mismo tiempo, la literatura relativa al Desarrollo Económico Local alerta sobre los peligros de la conjunción de intereses privados y del gobierno local para mantener esquemas de incentivos para una estructura productiva local declinante a nivel internacional en términos tecnológicos y/o de preferencias de los consumidores (Helmsing, 2001). Estas estrategias y la dependencia de la historia (path dependence) que generan pueden ser efectivas en el corto plazo, pero están destinadas al fracaso en el largo plazo, ante los cambios internacionales mencionados.

\section{La regulación del Área Aduanera Especial de Tierra del Fuego y de la Zona Franca de Manaos}

\subsection{La regulación del Área Aduanera Especial de Tierra del Fuego}

\subsubsection{Orígenes y evolución histórica}

Tierra del Fuego corresponde a la porción argentina de la Isla Grande de Tierra del Fuego (isla de soberanía compartida con Chile), ubicada en la región austral argentina, y para comienzos de la década del setenta mostraba un escaso nivel de población y una elevada proporción de extranjeros. A partir de la implementación del régimen especial, se aprecia un fuerte crecimiento poblacional (multiplicándose por más de ocho veces entre 1970 y 2010); así como un aumento en la proporción de los habitantes nacidos en la Argentina en relación a los nacidos en el extranjero.

La Ley 19.640, implementada en 1972, creó el Área Aduanera Especial de TDF con un régimen fiscal y aduanero especial para el área nacional del territorio de la Isla Grande de Tierra del Fuego. Las ventajas normativas y organizacionales otorgadas fueron importantes, y contemplaban, entre otros beneficios:

- la exención del Impuesto al Valor Agregado (IVA) sobre la compra de insumos y las ventas de los bienes finales producidos;

- la implementación de un arancel 0\% para las importaciones (tanto procedentes del exterior como del resto del territorio nacional) de insumos, medios de producción, y bienes finales; 
- las exportaciones destinadas al exterior y al resto del territorio nacional quedan exceptuadas de cualquier requisito cambiario y no estarán sujetas a derechos de exportación, contribuciones especiales u otras tasas con motivo de la exportación;

- la eliminación de restricciones al movimiento y transferencia de capitales y divisas;

- la exención del pago de tributos nacionales (incluye impuesto a los réditos, a las ventas, a las ganancias eventuales, a la transmisión gratuita de bienes y a otros impuestos nacionales que pudieran crearse en el futuro);

- el otorgamiento por parte del Estado de créditos blandos para las empresas que desearan instalarse en la región;

- la construcción financiada por el Estado provincial de infraestructura pública y el acceso gratuito a tierras con bajo costo fiscal.

Para gozar de los beneficios impositivos y aduaneros se debe demostrar que el origen de los bienes es el Área Aduanera Especial, es decir que los bienes se hayan producidos íntegramente en dicha área o que hayan sufrido un proceso productivo que implique, al tiempo de su venta al territorio nacional continental, una transformación o trabajo sustancial. Toda mercancía que no se haya acreditado como originaria del área especial carece de todo beneficio promocional a la hora de su introducción al Territorio Nacional Continental. En tal circunstancia, recibe el mismo tratamiento fiscal que una importación al territorio nacional continental desde el exterior. Por ende, para poder ser despachada a plaza deberá tributar todos los aranceles, impuestos y tasas que graven dichas operaciones al momento de su egreso del Área Aduanera Especial.

Durante la década del ochenta se hicieron muy evidentes ciertas consecuencias negativas del régimen de promoción industrial, como había sido implementado hasta entonces. La explosión demográfica en dicha década derivó en una fuerte especulación inmobiliaria, y generó presión sobre el uso del espacio físico, especialmente en Ushuaia. La ocupación ilegal de tierras y la proliferación de asentamientos precarios, derivaron en unas deficientes condiciones de vida de la población. Complementariamente, el deterioro de las cuentas fiscales y externas impuso la necesidad de ciertos ajustes en ambos frentes, lo que afectó a los regímenes de promoción en general, y al de TDF en particular.

A partir de 1989 los beneficios promocionales de la ley 19.640 fueron parcialmente suspendidos, así como la posibilidad de presentación y aprobación de nuevos proyectos industriales (decreto 1927/93). Por otro lado, los cambios estructurales a nivel nacional observados a lo largo de la década de los 90 -apertura, desregulación, privatizaciones, ajuste fiscal, etc. - llevaron a reconsiderar las 
perspectivas del Área Aduanera Especial de TDF. A lo largo de dicha década, se fue limitando el otorgamiento de incentivos a la radicación de empresas. Esto llevó al fin del pleno empleo en la región.

Sin embargo, para los proyectos aprobados y radicados con anterioridad a junio de 1989 se arribó a una situación de previsibilidad y a la posibilidad cierta de actualización tecnológica. Por un lado, se implementaron ciertas normas que contemplan la sustitución de productos, fabricados con los beneficios del marco normativo vigente (Decreto 479/95). Además, se establecieron nuevas regulaciones para la acreditación de origen por procesos productivos. Así se estableció que un producto será originario del Área Aduanera Especial de TDF cuando el valor CIF de los materiales importados empleados en su elaboración, no excedan el cincuenta por ciento $(50 \%)$ del valor FOB de exportación, o cuando se adecue a las procesos productivos básicos ${ }^{1}$.

Es importante remarcar que originalmente, mediante la ley 19.640 de 1972 y luego el decreto 1057/83, se fijaron actividades prioritarias para el régimen, que eran las que efectivamente tenían arancel $0 \%$ para la importación de bienes de capital e insumos, mientras que el resto de las actividades (no prioritarias) poseían una reducción del 50\% sobre el arancel vigente. Las actividades prioritarias deberían no competir con la producción del territorio nacional. Esta distinción de actividades prioritarias y no prioritarias se suprime mediante el decreto 1395/94. Sin embargo, el espíritu de no competencia con la producción del territorio nacional subsistió en el régimen de TDF: el régimen de sustitución de productos del decreto 479/95 establecía que los mismos deberían pertenecer a la misma rama de actividad o bien ser producto de procesos productivos similares, evitando que surgieran nuevos productos que compitieran con la producción del territorio nacional continental.

Por otro lado, en el año 2003 (decreto 490) y con vigencia hasta el año 2005 se habilitó la posibilidad de radicar nuevas empresas industriales, al amparo del régimen promocional de la ley 19.640, para la fabricación de productos nuevos, siempre que la producción de los mismos este habilitada en otros regímenes promocionales vigentes en el Mercosur y que no se produzcan en el Territorio Continental Nacional. No se exige el cumplimiento de estas dos condiciones para aquellos bienes que sean producidos exclusivamente para la exportación a terceros países.

Durante los últimos años, se implementaron algunas regulaciones orientadas a eliminar ciertas asimetrías existentes entre el Área Aduanera Especial de TDF y la ZFM. Así, por ejemplo, se extendió el plazo de vigencia de los derechos y

(1) Un proceso productivo básico puede ser definido como el conjunto mínimo de operaciones, realizadas en el establecimiento fabril, que caracteriza la efectiva industrialización de un determinado producto. Si este proceso se cumple íntegramente dentro del área beneficiada fiscalmente se obtiene la posibilidad de acceder a los beneficios fiscales establecidos 
obligaciones de la Ley 19.640 y los decretos n. 479/1995 y 490/2003, hasta el 31 de diciembre del año 2023 (decreto 1234/2007).

\subsubsection{La legislación en años recientes}

Posteriormente, se estableció la reapertura para nuevos proyectos orientados, por un lado, a promover la inclusión digital; y por el otro, a desarrollar a la electrónica como sector estratégico, con un horizonte de desarrollo local que permita una paulatina sustitución de importaciones de bienes de alto contenido tecnológico. En el año 2010 (decreto 916) se abrió por seis meses la presentación de nuevos proyectos destinados a la producción de computadoras portátiles (notebooks y netbooks) destinadas a proveer la oferta de estos productos en el marco del "Programa Conectar Igualdad", que se orienta a proporcionar computadoras a alumnos y docentes de educación secundaria de escuelas públicas. Este plazo luego se extendió hasta el 30 de junio del 2011 (decreto 39) para la fabricación de computadoras portátiles y se le incorporaron la producción de módems para redes de comunicaciones de celulares y tablets PC. Finalmente en el año 2012 (decreto 2623) se extendió hasta el 30 de junio del 2013 la presentación de nuevos proyectos para la fabricación de computadoras portátiles, módems, tablets PC, y se incorporaron cámaras fotográficas digitales y libros digitales (e-readers). En todos los casos señalados de apertura de nuevos proyectos los derechos y obligaciones, que a través de ellos se asuman, tendrán vigencia hasta el 31 de diciembre del 2023.

Sin embargo, lo que otorgó un verdadero impulso a la economía provincial fue la promulgación de la Ley 26.539, que en diciembre de 2009 estableció un aumento de los impuestos internos para los productos electrónicos importados o fabricados en Territorio Continental Nacional. Esta ley aumenta la tasa de impuestos internos y duplica la alícuota del IVA (tasa del 10,5\% al 21\%) a determinados productos tecnológicos importados del exterior, manteniéndose las exenciones impositivas establecidos por la Ley 19.640 a la industria electrónica del Área Aduanera Especial. Es decir que, al no alcanzar estos impuestos a los productos provenientes de dicha área, se genera un beneficio adicional para las empresas de dicha zona. Los productos incluidos en la ley 26.539 son: móviles/celulares, cámaras de fotos digitales y de video, monitores, GPS, planchas, secadores de pelo, estufas eléctricas, aire acondicionados, home theatres, plasmas, LCD y decodificadores de video. En cambio, las PC de escritorio, notebooks y netbooks no resultaron alcanzadas. La intención del Gobierno Nacional era acercar la regulación de TDF a aquella existente en la ZFM, y crear un polo tecnológico de similares características ${ }^{2}$.

(2) Es importante destacar que al momento de la revisión del presente trabajo, el decreto 117 del 17 de febrero de 2017 del Poder Ejecutivo Nacional reduce al 0\% el derecho de importación en el territorio nacional de "bienes de informática y telecomunicaciones", entre los que se encuentran las notebooks y tablets, y sus componentes; eliminando parte de los incentivos diferenciales del régimen de TDF. Esta decisión cambia significativamente la trayectoria regulatoria que el régimen tuvo bajo el gobierno anterior, generando incertidumbre sobre su futuro. 


\subsection{La regulación de la Zona Franca de Manaos}

Manaos, ciudad situada al norte de Brasil, es la capital del estado de Amazonas. Su población, concentrada en los márgenes de los ríos, ha vivido históricamente en condiciones de pobreza. El funcionamiento de la ZFM comienza en el año 1967, a través del Decreto Ley n. 288/67, buscando compensar la distancia que había entre la Amazonia y los grandes centros de consumo del país, lo que no le permitía desarrollar actividades económicas generadoras de empleo.

La ZFM se extiende a la orilla izquierda de los ríos Negro y Amazonas, 50 kilómetros debajo de la ciudad de Manaos y 70 kilómetros río arriba de dicha ciudad. Asimismo, se administra por medio de la Superintendencia de la Zona Franca de Manaos (Suframa), órgano vinculado al gobierno federal, a través de un Consejo de Administración. Es responsable de la ejecución de los programas y aprobar los proyectos de importación de productos extranjeros presentados en forma anual por las empresas establecidas en el área. Además, promueve la expansión de los recursos de ciencia y tecnología junto con instituciones académicas de la región y empresas del área. El Polo Industrial de Manaos, perteneciente a la zona franca, es uno de los polos industriales más importantes de América Latina.

Además de las medidas de promoción establecidas por el gobierno federal el área se beneficia con instrumentos de carácter estadual y municipal. Las principales medidas contempladas en el decreto 288 de 1967 y posteriores modificaciones establecen que:

- La entrada de productos extranjeros a la ZFM, destinados al consumo interno o la industrialización estará exenta de impuestos a la importación y del Impuesto a los Productos Industrializados (IPI) (Art. 3). Esa exención se mantiene para las mercancías consideradas que sean exportadas al exterior, o sea, a terceros países (Art. $3 \S 3$ ). Asimismo, en términos del IPI, están exentas de dicho impuesto todas las mercancías producidas en la ZFM, que se destinen al consumo interno de la región o a ser exportadas al territorio nacional (Art. 9).

- La exportación de bienes de origen nacional para el consumo o la industrialización en la ZFM, o para su posterior re-exportación en el extranjero, será para todos los impuestos contemplados en la legislación vigente equivalentes a una exportación brasilera hacia el extranjero (Art. 4).

- Las exportaciones de la ZFM para el extranjero están exentas del impuesto de exportación (Art. 5). En cambio, los bienes de origen extranjero recibidos en stock en la zona franca, cuando sean vendidos a cualquier parte del territorio nacional, estarán sujetas al pago de todos los impuestos de importación desde el extranjero (Art. 6). 
- En el caso de los productos industrializados ${ }^{3}$ mediante un proceso productivo básico en la ZFM así como sus respectivas partes y piezas, que hayan sido aprobados por el Suframa y que sean exportadas al territorio nacional, estarán sujetos al pago del impuesto de importación sobre los insumos de origen extranjero con una reducción del $88 \%$ sobre cada arancel ad valorem a la importación (Art. 7, especialmente el § 4). Este criterio de reducción arancelaria corre para todos los bienes, excepto para los bienes informáticos y los automóviles, tractores y otros vehículos terrestres (donde se incluyen las motos, bicicletas y similares), incluyendo sus partes y piezas.

- Para los bienes informáticos y los automóviles, tractores y otros vehículos terrestres, incluyendo sus partes y piezas, el coeficiente de reducción del impuesto será equivalente al porcentaje de mano de obra e insumos nacionales respecto al total de la mano de obra e insumos utilizados directamente en la fabricación de dicho producto ${ }^{4}$ (Da Costa Oliveira, 2011, p. 55; y Art. 7 § 1).

- Para los casos de los automóviles, tractores y otros vehículos terrestres, incluyendo sus partes y piezas, que sean exportadas al territorio nacional, estarán sujetos al pago del impuesto de importación sobre los insumos de origen extranjero, conforme al coeficiente de reducción mencionado en el punto anterior, al cual se le adicionaran 5 puntos porcentuales (Art. 7 §).

- Por otra parte, las mercancías de origen nacional destinadas a la ZFM con la finalidad de ser reexportadas para otros puntos del territorio nacional pagaran todos los impuestos vigentes a la producción y circulación de mercancías en el país (Art. 8).

A los efectos de tener acceso a los beneficios ligados a la reducción de los impuestos de importación y del IPI en los productos industrializados que se dirigen al territorio nacional las empresas deben cumplir una serie de requisitos:

- incrementar la oferta de empleo;

- conceder beneficios sociales a los trabajadores;

(3) Se consideran productos industrializados los resultantes de procesos de transformación definidos por la ley del Impuesto sobre productos industrializados (IPI).

(4) El coeficiente de reducción de su alícuota ad valorem se calcula de de la siguiente manera (Art. 7 § 1):

$$
r(j)=\frac{\sum_{i} C I(j)_{i}^{\text {Brasil }}+W(j)^{\text {Brasi }}}{\sum_{i} C I(j)_{i}+W(j)^{\text {Brasil }}}
$$

Donde $C I$ representa los consumos intermedios (en valores) de los distintos insumos $i$ para la producción del bien $j$, y W representa los salarios pagados en la producción directa de dicho bien $j$, sujeto a la reducción arancelaria. Por ende, el coeficiente representa la incidencia de los insumos locales en el total, y aumenta cuando dicha participación es mayor, basada en el aumento de la integración productiva al interior del país para el producto $j$. Se excluyen consideraciones de segundo orden en términos de orígenes de insumos, por lo que no se consideran de origen extranjero los insumos importados del exterior de empresas de la ZFM proveedoras de insumos a otras empresas de la región, en el cálculo del coeficiente de estas últimas. 
- incorporar tecnología de productos o procesos;

- obtener niveles crecientes de productividad;

- reinvertir sus ganancias en la región;

- atender a los límites anuales de importación que constan en la resolución aprobatoria del proyecto por parte de la Suframa (Ley 8387/91, art 7).

Fuera del marco del decreto-ley n. 288 de 1967 y sus modificatorias, existen otros beneficios fiscales a las empresas localizadas en la ZFM (Da Costa Oliveira, 2011, p. 41):

- Reducción en un 75\% del Impuesto a la Renta de Personas Jurídicas (IRPJ), incluyendo adicionales para emprendimientos clasificados como prioritarios para el desarrollo regional;

- Exención de la contribución para el PIS/Pasep (Programa de Integración Social / Programa de Formación del Patrimonio del Servicio Público) y del Cofins (Contribución al Financiamiento de la Seguridad Social) en las operaciones internas de la ZFM;

- Restitución parcial o total, variando entre el 55\% y el 100\% (dependiendo del proyecto) del Impuesto sobre Operaciones Relativas a la Circulación de Mercaderías y sobre la Prestación de Servicios de Transporte Interestatal e Intermunicipal y de Comunicaciones (ICMS);

- Crédito en el ICMS concedido por la Secretaría de Hacienda del Estado de Amazonas a los productos oriundos de otros estados brasileros destinados al consumo o industrialización en la ZFM;

- Exención del Impuesto sobre la Propiedad Predial y Territorial Urbana, Tasas de Servicios de Recolección de Basura, de Limpieza Pública, de Conservación de Calles y Zonas de Recreación Públicas, y Tasas de Licencia para las empresas que generen un mínimo de 500 empleos, de forma directa, desde el inicio de sus actividades, que debe ser mantenido (como mínimo) para seguir gozando de la exención (Ley Municipal n. 427/1998);

- Exención o reducción del Impuesto sobre Servicios (ISS) para las empresas prestadoras de servicios con proyectos aprobados por la Prefectura Municipal de Manaos (Decreto Municipal n. 5626/86);

- Subsidio del Flete desde y hacia Manaos. Los costos de transporte que correspondería abonar hasta y desde Manaos, fueron equiparados al que correspondería abonar desde y hacia en el puerto de Santos, en el Estado de San Pablo (aproximadamente U\$S 2.600 por un contenedor de 40 pies); tanto para la 
exportación de productos finales como para la compra de insumos, componentes, bienes intermedios o material de embalaje (Portaría n. 355/98 de la Suframa);

- Créditos para la formación de capital para las empresas que con proyectos aprobados por Suframa, otorgado por el Finam (Fondo Industrial de Amazonia).

En términos del sistema de ciencia y técnica a nivel regional, es importante destacar que las empresas productoras de bienes y servicios del sector informático deben invertir, anualmente, el 5\% de su facturación bruta en actividades de Investigación y Desarrollo a ser realizadas en la Amazonia.

En dicho contexto, en el año 2000 comenzó a funcionar el Instituto de Tecnología Genius, un organismo privado orientado a promover innovaciones tecnológicas en las áreas electrónicas y de telecomunicaciones. Complementariamente, se ha creado el Centro de Biotecnología de la Amazonia, en 2002; y el Centro de Ciencia, Tecnología e Innovación del Polo Industrial de Manaos (CTI PIM), creado por la Suframa en 2003.

\section{Análisis económico del Área Aduanera Especial de Tierra del Fuego y de la Zona Franca de Manaos 5}

\subsection{Metodología y disponibilidad de información}

La metodología a emplear en la siguiente sección para analizar la evolución económica de TDF y de la ZFM, así como compararlas, es realizar un análisis descriptivo de las variables relevantes: producción, exportaciones, importaciones, empleo, y producto por trabajador, entre otras.

Las fuentes de información se aclaran en cada uno de los gráficos o tablas en particular; donde para el caso de la ZFM predominan las estadísticas elaboradas por la Suframa, mientras que en TDF las fuentes de información son más diversas. Es importante destacar la escasa extensión temporal de las series consideradas. Ante esta limitación, la comparación entre las zonas (subsección 3.4) se realiza para el período 2003-2013; mientras que en algunas variables para los análisis individuales de TDF (subsección 3.2) y de la ZFM (subsección 3.3) se ha aprovechado la mayor disponibilidad de información. En todos los casos, se está lejos de disponer de una cantidad de observaciones que permita realizar estimaciones econométricas evitando problemas de sesgos en los valores estimados y de no identificar correctamente la significatividad estadística (Goldberger, 1991, p. 248-250). Por ende, se ha descartado la posibilidad de realizar análisis econométricos del estilo de datos de panel, cruzando información en términos de series de tiempo y distintas unidades de

(5) En la presente sección, ante la carencia de estadísticas con la ZFM como unidad de análisis, el análisis económico relativo a la ZFM (y su posterior comparación con TDF) se centrará principalmente en estadísticas del Polo Industrial de Manaos (PIM), principal núcleo de actividad de la ZFM. Por lo tanto, salvo que se aclare específicamente lo contrario, se utilizarán indistintamente las denominaciones Manaos, PIM y ZFM. 
observación (zonas), que permitan detectar correlaciones y causalidades generales incorporando información de ambas zonas, así como profundizar el análisis comparativo.

\subsection{Análisis económico del Área Aduanera Especial de Tierra del Fuego}

Como resultado de un esquema de incentivos de varias décadas, el sector industrial se ha posicionado como el sector económico más importante de TDF. En términos de productividad (Gráfico A.1 del Anexo), los sectores de industria y servicios (excluyendo el comercio, pero donde se incluyen importantes actividades a nivel regional, como el turismo ${ }^{6}$ ) son los de mayor producto medio por trabajador, convergiendo en los últimos años debido al leve crecimiento de la productividad del sector servicios, y al fuerte decrecimiento de la productividad industrial (en un contexto de crecimiento del empleo).

Como podemos ver en el Gráfico 1, la evolución de la ventas de TDF al territorio nacional continental ha sufrido un punto de inflexión a partir del 2010, fruto de los cambios regulatorios ya mencionados.

Gráfico 1

Tierra del Fuego: Evolución de las ventas por producto al territorio nacional continental

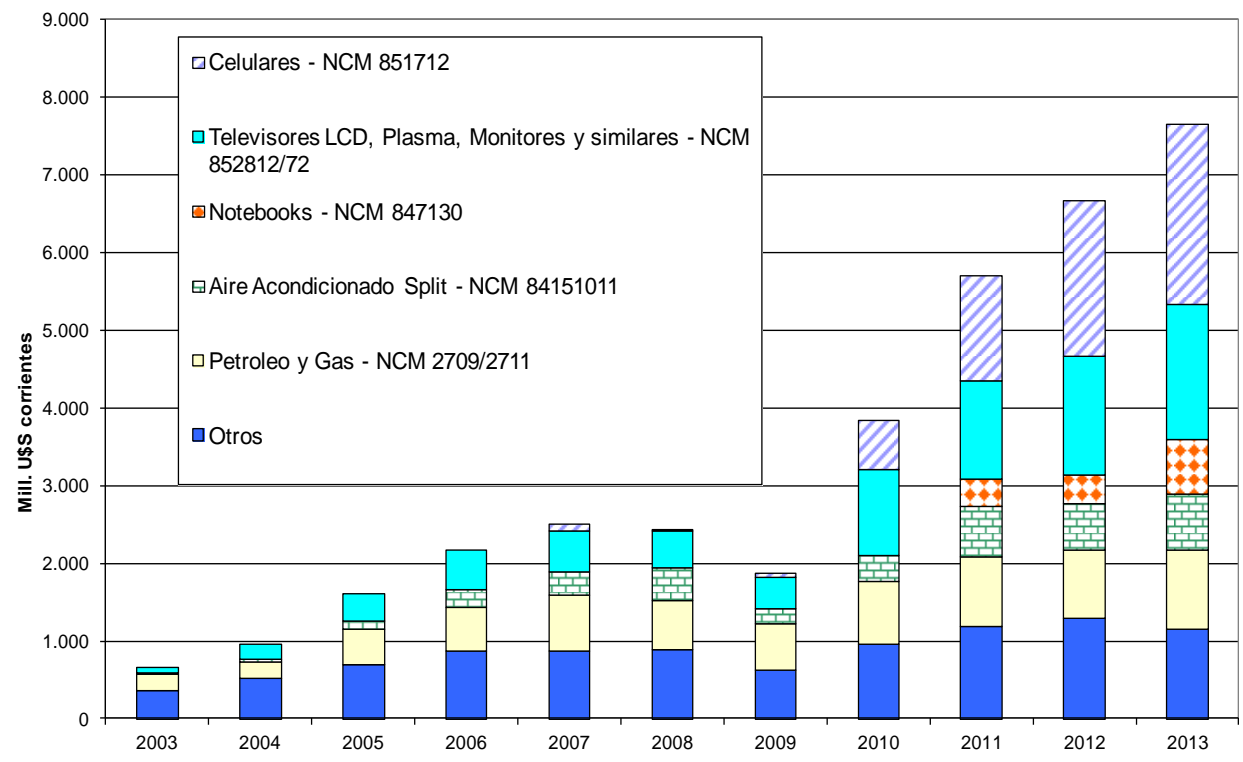

Fuente: Elaboración propia en base a Aduana.

(6) Sobre este tópico, es importante remarcar la existencia de experiencias exitosas de desarrollo local basadas en el sector turismo a nivel internacional (Rogerson, 2002) así como en la Argentina en particular; como en el caso de El Chaltén en la región patagónica, especializado en turismo de aventura y trekking mediante la creación de reservas naturales y la restauración paisajística (Schinelli; Vacca, 2007). 
Desde dicho año, el fuerte incremento de dichas ventas ha sido liderado por los teléfonos celulares y las notebooks; acompañadas por las ventas de televisores LCD y similares, y aires acondicionados Split, dos productos de relativamente mayor inserción en el primer lustro de la década. Esto ha hecho caer la participación del petróleo y gas las ventas totales al territorio nacional. Sin embargo, el gas sigue siendo el principal y casi excluyente producto exportado a terceros mercados desde TDF (Tabla A.1 del Anexo).

Es importante remarcar que el fuerte crecimiento de la producción de TDF orientada al territorio nacional permitió que, para el año 2012, en varios productos electrónicos la producción nacional (principalmente explicada por TDF) llegue a cubrir gran parte del consumo aparente (Luppi, 2013); acaparando más del 90\% del mismo en celulares, televisores, hornos microondas, videocámaras, reproductores de DVD, y monitores LCD para PC. Los principales productos donde queda margen para sustituir productos importados por producción nacional son equipos de audio (la producción nacional representa el 21\% del consumo aparente), reproductores MP3 y MP4 (33\%), cámaras fotográficas (55\%), PC de escritorio (78\%), y notebooks y netbooks $(67 \%)$.

Sin embargo, en términos del desarrollo de proveedores dentro del territorio nacional continental, el régimen de TDF ha logrado una escasa integración, especialmente en la provisión de insumos de mayor complejidad técnica. Como vemos en la Tabla 1, los productos plásticos en formas primarias (para su posterior transformación) acaparan casi la mitad de las ventas del territorio nacional a TDF para 2011-2013; donde se pueden remarcar otros insumos de baja complejidad técnica como las cajas y etiquetas de papel o cartón para el packaging de los productos ( $8 \%$ de las ventas a TDF), y diversos insumos de la industria textil: colorantes y pinturas (5\%), hilados $(3 \%)$, y filamentos (1\%). Más allá de estos insumos industriales de baja complejidad técnica, el segundo producto en importancia en la provisión desde el territorio nacional está vinculado con la actividad turística: se trata de las vans y colectivos para el transporte de personas (11\%). En términos de la industria electrónica, el único subsector que aparenta tener algún grado de desarrollo de proveedores específicos en el territorio nacional (más allá de los productos plásticos y del packaging), es la producción de aires acondicionados, heladeras y otros electrodomésticos. Estos sectores podrían explicar parte de las importaciones de insumos de hierro y acero, y de las bombas y compresores de aire. Las partes específicas para aires acondicionados representaron el $1 \%$ de las ventas del territorio nacional a TDF. En cambio, no se registraron en toda la década ventas desde el territorio nacional a TDF de partes específicas de celulares, notebooks, y televisores color. 
Análisis comparativo de la Zona Franca de Manaos y el área aduanera especial de Tierra del Fuego

Tabla 1

Tierra del Fuego: Niveles y evolución de las compras al territorio nacional, por producto

\begin{tabular}{|c|c|c|c|c|c|}
\hline $\mathrm{NCM}$ & Descripción & $\begin{array}{l}\text { Prom. } \\
2003-2005 \\
(\cup \$ S)\end{array}$ & $\begin{array}{l}\text { Prom. } \\
2011-2013 \\
\text { (U\$S) }\end{array}$ & $\begin{array}{c}\text { Part. } \\
2011-2013\end{array}$ & $\begin{array}{l}\text { Tasa prom. } \\
\text { de } \\
\text { crecimiento } \\
\text { 2003-2013 }\end{array}$ \\
\hline $3901-14$ & Plasticos primarios & 40.386 .851 & 129.555 .801 & $45 \%$ & $15 \%$ \\
\hline 8703 & Vans y colectivos para transporte de personas & 7.016 .883 & 32.387 .358 & $11 \%$ & $23 \%$ \\
\hline $4819 / 21 / 23$ & Cajas, etiquetas y similares de papel o cartón & 4.651 .970 & 21.839 .163 & $8 \%$ & $22 \%$ \\
\hline 32 & Colorantes, pinturas, barnices, enduídos y tintas & 3.276 .243 & 14.185 .661 & $5 \%$ & $16 \%$ \\
\hline $870421 / 31$ & Camionetas para transporte de mercancías & 3.752 .518 & 13.818 .903 & $5 \%$ & $17 \%$ \\
\hline 2402 & Cigarrillos & 2.988 .460 & 9.928 .317 & $3 \%$ & $16 \%$ \\
\hline 8708 & Autopartes - Radiadores & 1.109 .230 & 8.056 .303 & $3 \%$ & $24 \%$ \\
\hline $5205 / 06 / 07$ & Hilados de algodón & 9.175 .201 & 7.933 .503 & $3 \%$ & $-3 \%$ \\
\hline 73 & $\begin{array}{l}\text { Productos elaborados de hierro o acero (techos, } \\
\text { puertas, ventanas, cubas, tubos, rejas, persianas } \\
\text { metálicas, garrafas, radiadores, etc.) }\end{array}$ & 13.354 .478 & 6.368 .572 & $2 \%$ & $-9 \%$ \\
\hline 72 & $\begin{array}{l}\text { Productos primarios de hierro o acero (laminados, } \\
\text { barras, perfiles, alambre, etc.) }\end{array}$ & 886.233 & 5.443 .841 & $2 \%$ & $24 \%$ \\
\hline 2523 & Cementos hidráulicos & 1.895 .132 & 3.604 .570 & $1 \%$ & $7 \%$ \\
\hline 8418 & $\begin{array}{l}\text { Partes de refrigeradores, heladeras, freezers y } \\
\text { similares }\end{array}$ & 2.061 .655 & 3.417 .146 & $1 \%$ & $11 \%$ \\
\hline 54 & Filamentos sintéticos y similares & 1.760 .126 & 3.272 .301 & $1 \%$ & $8 \%$ \\
\hline 8415 & Partes de aires acondicionados & 1.122 .277 & 2.821 .736 & $1 \%$ & $14 \%$ \\
\hline 8414 & Bombas y compresores de aire & 1.066 .313 & 1.607 .808 & $1 \%$ & $6 \%$ \\
\hline $3915-26$ & Plásticos semiterminados y terminados & 754.953 & 1.183 .485 & $0 \%$ & $11 \%$ \\
\hline $870422 / 23$ & Camiones & 322.025 & 266.387 & $0 \%$ & $-3 \%$ \\
\hline 8708 & Otras autopartes & 1.219 .051 & 5.068 & $0 \%$ & s.d. \\
\hline $85177010 / 21 / 99$ & $\begin{array}{l}\text { Partes específicas de celulares (circuitos } \\
\text { electrónicos específicos, antenas, y otras partes } \\
\text { específicas) }\end{array}$ & 0 & 0 & $0 \%$ & $0 \%$ \\
\hline 847330 & Partes específicas de computadoras & 0 & 0 & $0 \%$ & $0 \%$ \\
\hline 85299020 & Partes específicas de televisores color & 0 & 0 & $0 \%$ & $0 \%$ \\
\hline \multicolumn{2}{|r|}{ Otros } & 21.808 .321 & 21.805 .744 & $8 \%$ & $1 \%$ \\
\hline \multicolumn{2}{|r|}{ Total } & 118.607 .923 & 287.498 .288 & $100 \%$ & $11 \%$ \\
\hline
\end{tabular}

Fuente: Elaboración propia en base a Aduana.

A pesar de este contexto, Luppi (2013) remarca la existencia de proveedores en el territorio nacional argentino de circuitos electrónicos impresos, que abastecen en el mercado interno a firmas de los sectores de instrumental médico, telecomunicaciones, seguridad, y automotriz, entre otras. Sin embargo, los productores de TDF utilizan circuitos electrónicos impresos importados. Con respecto a los circuitos electrónicos integrados o "chips", los de mayor complejidad técnica, el autor remarca que la capacidad productiva argentina es menor.

La contracara del crecimiento de la actividad industrial en TDF, orientada a vender al territorio nacional, complementado por el escaso desarrollo de proveedores en dicho territorio ya mencionado, ha sido un creciente déficit comercial con el exterior (Gráfico 2), fuertemente determinado por las importaciones de insumos para dicha industria. Luppi (2013) remarca que el ahorro de divisas por el aumento de la producción nacional de electrónicos (principalmente motorizada por TDF) sería relativamente bajo, destacando que la actividad se centra en el ensamblado de diseños no propios, donde con el "kit" de partes y componentes se está importando el valor agregado correspondiente al desarrollo del producto. La tabla A.1 del Anexo muestra que los principales productos de importación de TDF son insumos, como partes de celulares, radios, televisores, y computadoras; circuitos integrados, bombas, baterías y plásticos, entre otros. Por otro lado, las exportaciones son 
insignificantes en relación a las importaciones (solo se exportan productos primarios y algunas radios y similares). Ante exportaciones al exterior y compras desde el territorio nacional poco significativas, el déficit con el exterior está explicado por la evolución de las importaciones, necesarias para aumentar la producción orientada al territorio nacional; mientras que el creciente superávit con dicho territorio está explicado por dichas ventas. Por ende, déficit con el exterior y superávit con el territorio nacional evolucionan conjuntamente. Más allá de su signo, ambos saldos han crecido fuertemente en términos absolutos con la reactivación de la producción y el empleo a partir del 2010.

\section{Gráfico 2}

Tierra del Fuego: Flujos comerciales con el territorio nacional y el exterior

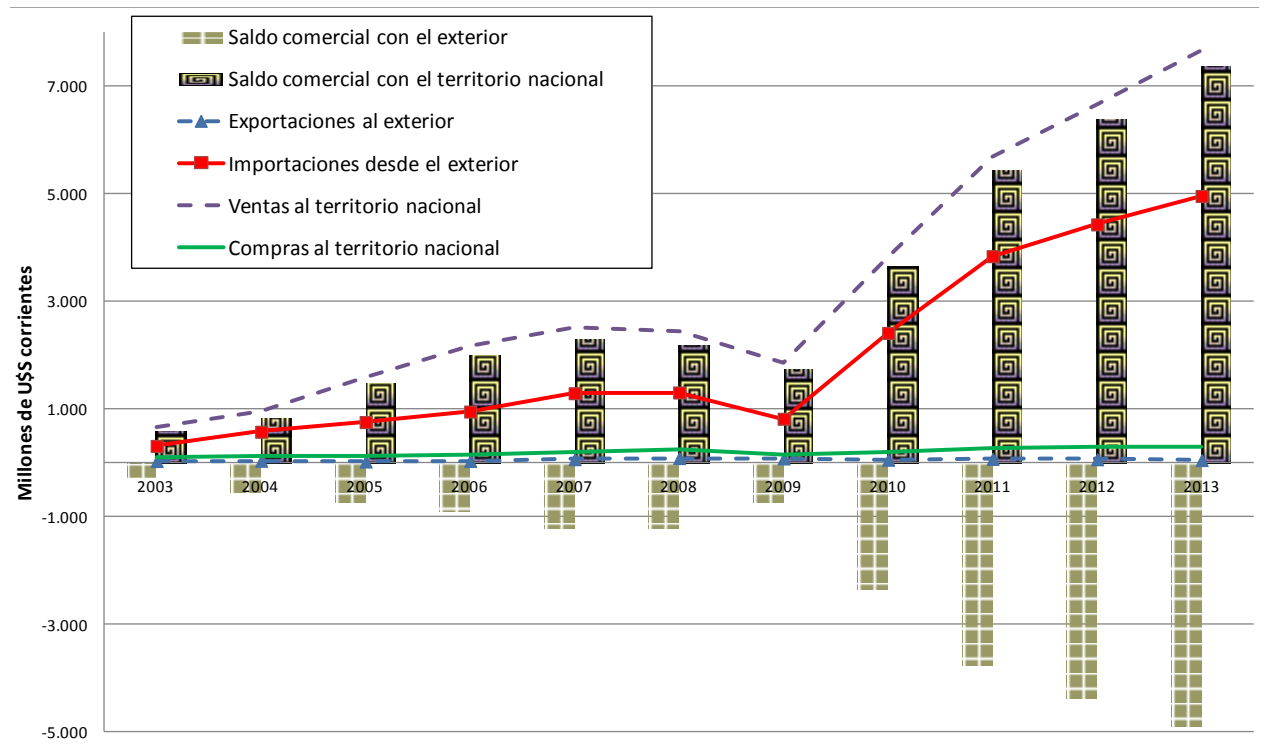

Fuente: Elaboración propia en base a Aduana.

Párrafo aparte amerita la concentración de la producción industrial del régimen de TDF, y su organización. Como mencionan Schorr y Porcelli (2014), mientras que para 2005 las 30 empresas de electrónica y afines pertenecientes al subrégimen de $\mathrm{TDF}^{7}$ ocupaban al $6.1 \%$ de los empleados en TDF, y acaparaban el $2 \%$ de las importaciones totales del país, para 2013 dichas cifras habían ascendido a $22.1 \%$ y $6.1 \%$, respectivamente. Esto va en línea con los efectos del cambio del marco regulatorio en el sector electrónico, aunque su impacto al interior del mismo ha sido muy heterogéneo: Brightstar Fueguina, una empresa especializada en teléfonos celulares, pasó de acaparar el 4.2\% de las importaciones de las empresas electrónicas del sub-régimen en 2005-2009 al 36.5\% en 2013; seguida por Iatec (con

(7) Schorr y Porcelli (2014) denominan empresas del "sub-régimen industrial" a aquellas empresas con proyectos aprobados por la autoridad de aplicación, un subconjunto específico de empresas (las de mayor relevancia) dentro del régimen general de TDF. 
varias líneas de producción, como los aires acondicionados, hornos microondas, DVDs, televisores, notebooks y celulares) que subió del $0.1 \%$ al $10.6 \%$ entre dichos períodos (Schorr; Porcelli, 2014).

Sin embargo, el correlato del fuerte déficit comercial con el exterior de TDF es la reducción de las importaciones de productos finales en el territorio nacional. Por ejemplo, a partir del 2010, la producción y ventas al territorio nacional de notebooks de TDF ha sustituido en parte a las importaciones de las mismas desde el exterior (Gráfico 3). Considerando que no es posible identificar la totalidad de los insumos importados para la producción de dichas notebooks, según los insumos que hemos podido identificar, el ahorro de divisas en ese producto ha sido positivo. Es decir que la reducción de importaciones de notebooks desde terceros mercados ha sido mayor que el aumento de las importaciones de partes del $\mathrm{TDF}^{8}$. Sin embargo, el precio promedio de importación de notebooks desde el exterior es significativamente menor al de las compras desde TDF (cerca de la mitad, con una brecha que ha sido creciente), lo que implica un alto costo a ser pagado por los consumidores.

Gráfico 3

Importaciones del territorio nacional argentino de notebooks, según origen; e importaciones de partes de computadoras desde el TDF

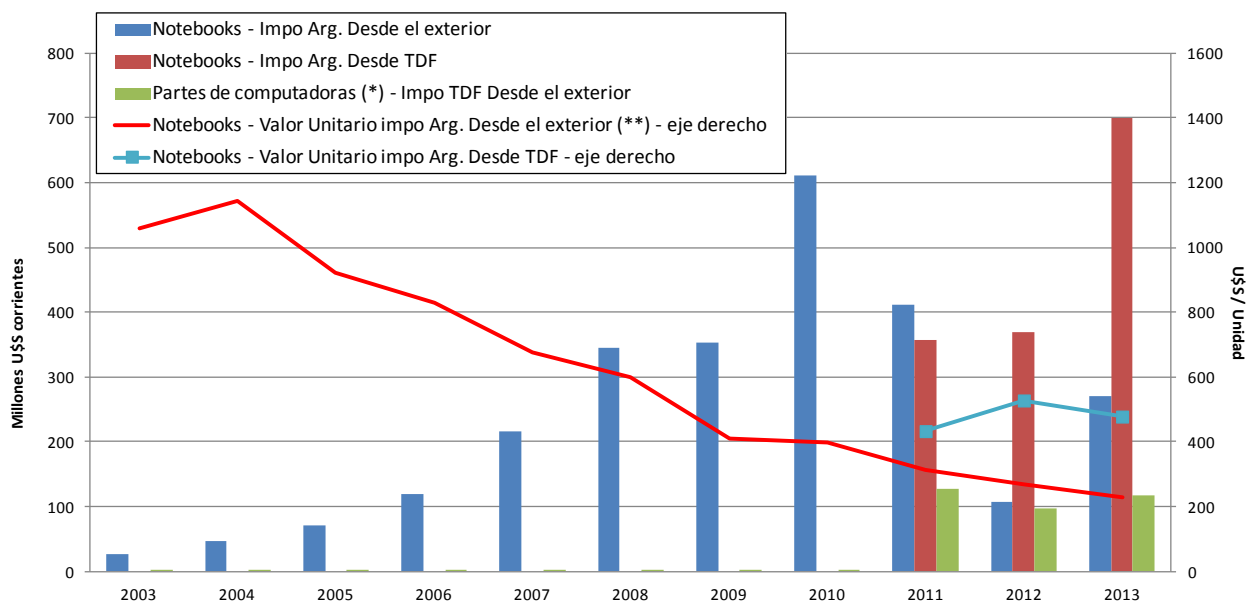

Fuente: Elaboración propia en base a Aduana y Comtrade.

(*) Nota: Se contemplan las partes de notebooks correspondientes al HS02 847330, donde se incluyen partes de otro tipo de computadoras (del HS02 8471), pero se consideran esencialmente como partes de notebooks porque es el único tipo de computadora del HS02 8471 que se exporta al territorio nacional continental. Asimismo, puede haber otras partes de notebook no pertenecientes al HS02 847330 que no han sido contempladas.

(8) Es llamativo que el fuerte aumento de las ventas de TDF al territorio nacional en 2013 (tanto en valores como en cantidades, que no se presentan en el gráfico), casi no ha impactado en un aumento en las importaciones de partes (ni en valores, ni en cantidades). Las hipótesis posibles son un fuerte proceso de sustitución de importaciones de insumos en dicho producto (algo que parece poco factible para explicar la magnitud del cambio del coeficiente de importaciones en solo un año); o alguna inconsistencia o falla en las estadísticas, lo que quitaría fuerza al argumento presentado sobre el ahorro de divisas en el caso de las notebooks. 
La evolución de la inversión en TDF muestra un comportamiento errático, tanto en los niveles como en su composición sectorial. El Gráfico 4 muestra claramente que luego de años de bajas inversiones en el sector industrial durante comienzos de la década del dos mil, la misma se fue recuperando, especialmente a partir de los cambios regulatorios del año 2010. Sin embargo, para el bienio 2012 2013, la inversión del sector industrial se ha tornado nuevamente decreciente, luego de cuatro años de continuo crecimiento. En términos de su composición sectorial, se puede apreciar que son los sectores de electrónica y de productos químicos los que motorizan las crecientes inversiones a partir del 2010, donde se destacan asimismo la incidencia de las inversiones en biocombustibles en el trienio 2008-2010. Es interesante remarcar que el crecimiento de las inversiones en productos químicos ha sido más estable que en el sector electrónico, que tuvo un sendero inversor más errático: se aprecia en el gráfico una fuerte reacción inversora en 2011 con la reapertura de proyectos, que posteriormente se apaciguó.

Gráfico 4

Tierra del Fuego: Montos anuales de anuncios de inversión en la industria manufacturera por subsector

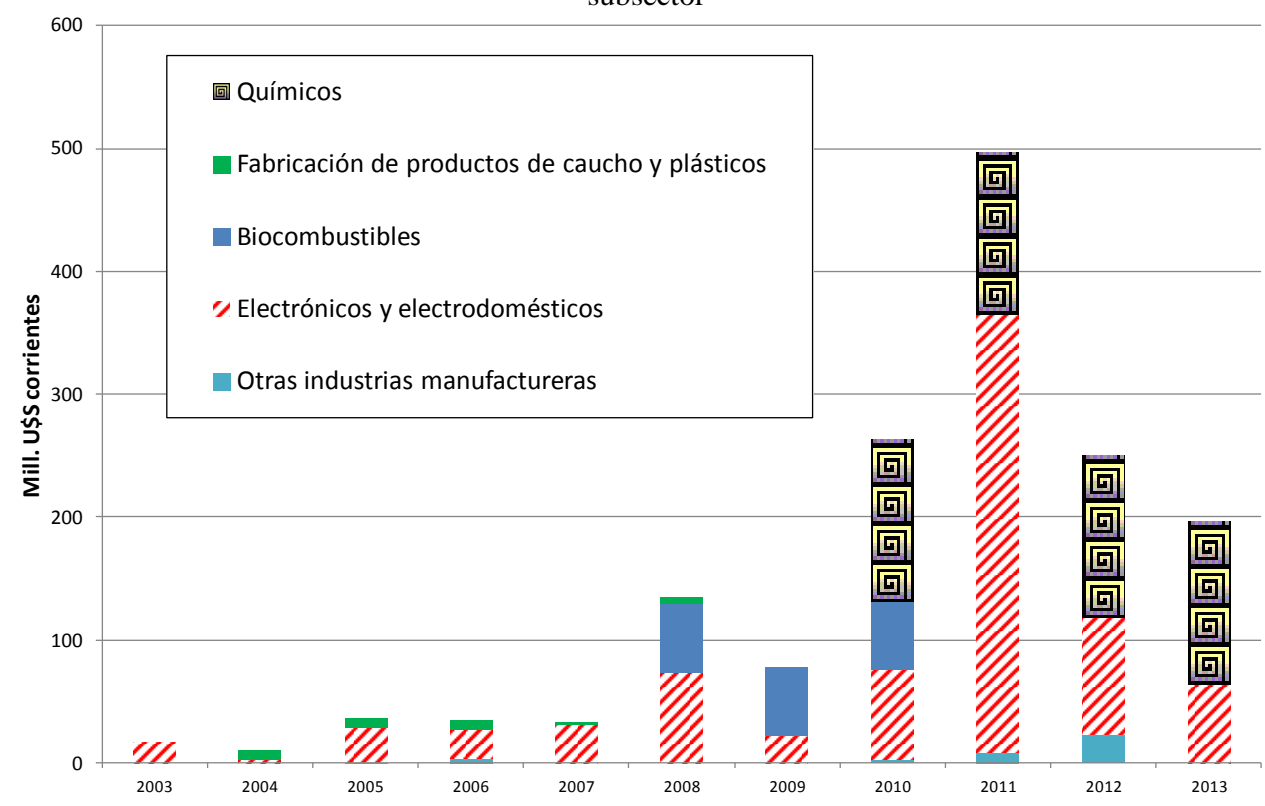

Fuente: Elaboración propia en base al CEP.

\subsection{Análisis económico de la Zona Franca de Manaos}

Como podemos apreciar en el Gráfico 5, la evolución de la producción en la ZFM ha sido oscilante hasta la década del dos mil. Sin embargo, a partir del 2003 se consolidó un sendero de fuerte y estable crecimiento; con la excepción del año 2009, donde se aprecian los efectos de la crisis internacional, y de un año excepcionalmente 
expansivo en el 2011. En términos de composición sectorial, en la década de los dos mil perdió peso relativo el sector de electrónicos en general (que hasta mediados de los noventa acaparó cerca del $60 \%$ del Valor Bruto de Producción - VBP -, y para fines del dos mil rondaba el 30\%), a manos de los sectores de informática, de "dos ruedas" (motos, bicicletas, y similares), y en menor medida de los productos químicos; así como creció también el sector metalúrgico, desde niveles originales mucho menores.

Gráfico 5

Polo Industrial de Manaos: Evolución del Valor Bruto de Producción por sector

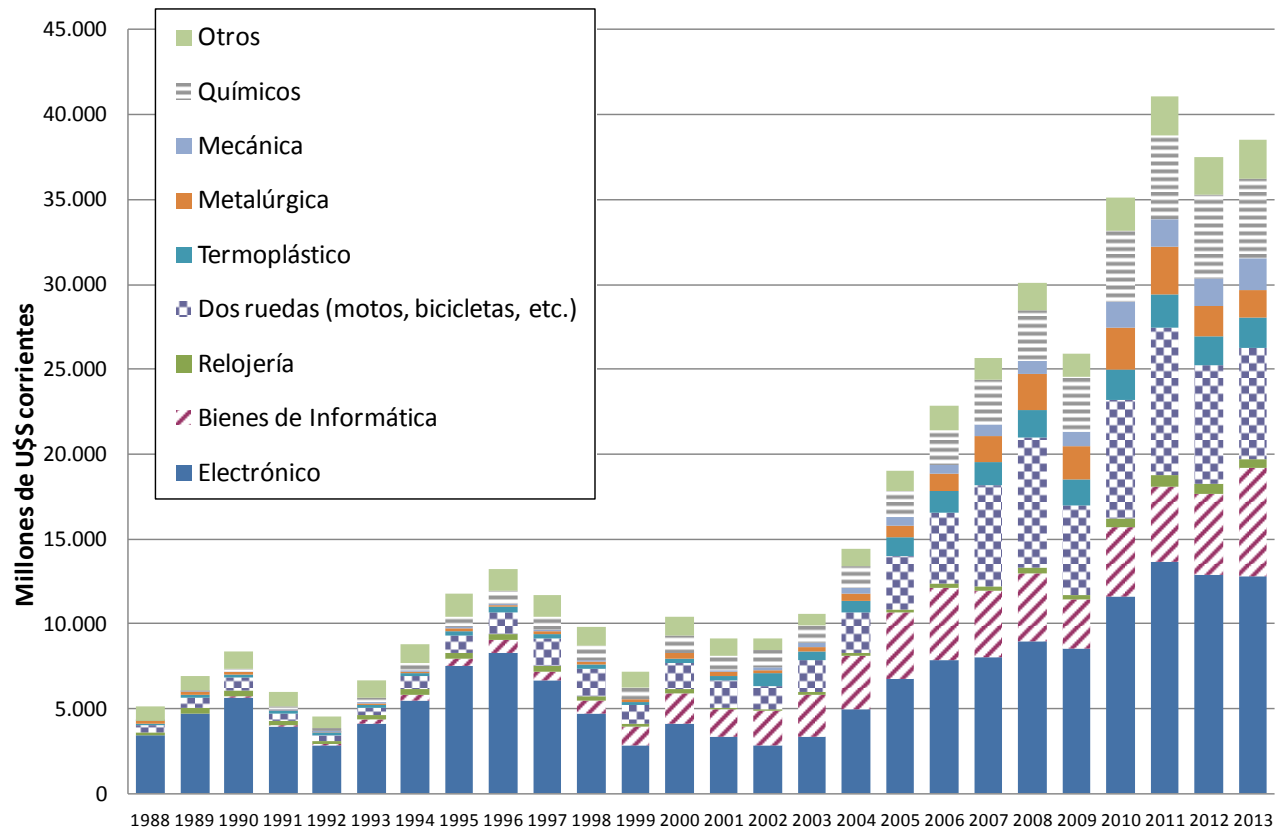

Fuente: Elaboración propia en base a Suframa.

La Tabla A.2 del Anexo muestra la evolución de los principales productos de la ZFM. Allí podemos apreciar que los productos más dinámicos en la última década están relacionados con el sector de electrónica en general (televisores, aires acondicionados, cámaras fotográficas, "home theater", entre otros), informática (monitores, microcomputadoras, PCIs, etc.), motocicletas, y productos de plástico (juguetes, encendedores y máquinas de afeitar; donde es importante destacar que Gillete posee en Manaos su mayor planta fabril de Sudamérica, como remarcan Bruera et al., 2012). El fuerte crecimiento de la producción tuvo como base la expansión de las inversiones en la ZFM, que han sido crecientes durante toda la 
década (Gráfico A.2 del Anexo). Los sectores más dinámicos han sido el electrónico (incluyendo al sector informático) ${ }^{9}$, el de "dos ruedas", y el de productos plásticos.

En términos comerciales, como se aprecia en el Gráfico 6, la ZFM destina gran parte de su producción al mercado del territorio nacional de Brasil, mientras que las exportaciones a terceros mercados participan de forma poco significativa de las ventas, situación estructural en las últimas dos décadas. En cuanto a las compras de dicha zona, el mercado de importación y las compras al territorio nacional poseen niveles y evoluciones muy similares. Por ende, en la última década, en un contexto de crecimiento de la producción y las ventas, ha aumentado persistentemente el déficit externo de la zona. Sin embargo, este déficit se ve sobrecompensado por el fuerte y creciente superávit con el territorio nacional.

\section{Gráfico 6}

Polo Industrial de Manaos: Comercio con el exterior y el mercado interno brasileño del sector industrial

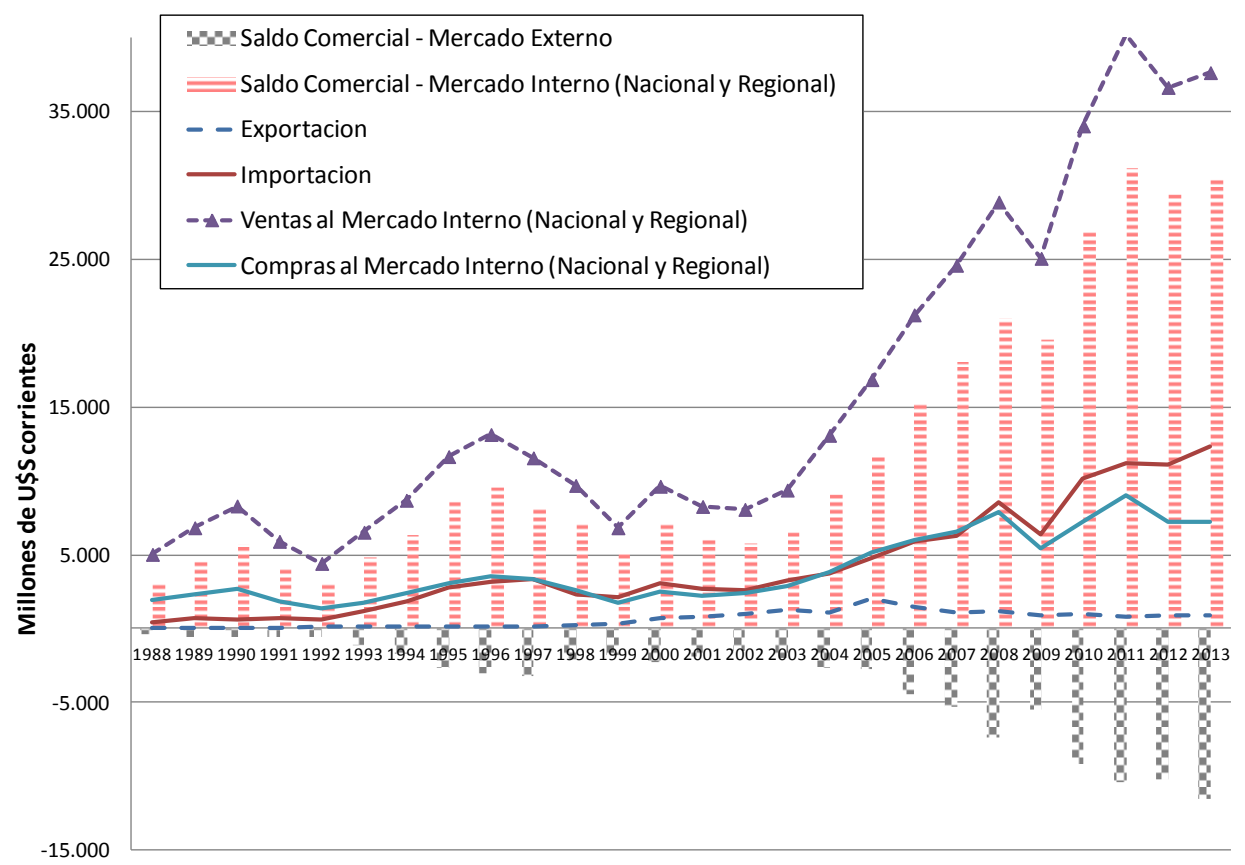

Fuente: Elaboración propia en base a Suframa.

A nivel de sectores, puede apreciarse en el Gráfico 7 que el comportamiento sectorial en términos de integración es heterogéneo. El sector electrónico presenta una dependencia de insumos importados estructuralmente más elevada que el resto.

(9) Es importante remarcar que la fuente utilizada no explicita al sector informático diferenciado del sector electrónico para el caso de las inversiones, lo que sí hace para otras variables. Sin embargo, por los volúmenes considerados, suponemos que está incluido en los electrónicos en general, y no así en los “otros sectores”, que en la fuente original deja poco margen para la inclusión del sector informático en dicha categoría. 
En cambio, la producción de motos, bicicletas y similares, uno de los sectores que más ha crecido en términos de valor de producción en la década de los dos mil (ver Gráfico 5), exhibe un elevado nivel de integración nacional. En este sentido, es importante remarcar que Honda posee en Manaos una de sus mayores fábricas fuera de Japón, donde se producen más de un millón de motocicletas al año, destinadas tanto al mercado brasileño como a la exportación ${ }^{10}$. Asimismo, Harley Davison posee en Manaos su única fábrica de motocicletas fuera de los Estados Unidos (Bruera et al., 2012). Por otro lado, otro de los sectores de fuerte integración es el mecánico, aunque la misma se vio reducida hacia finales del período bajo estudio.

\section{Gráfico 7}

Polo Industrial de Manaos: Participación de los insumos importados en el total de la oferta regional de insumos para diversos sectores industriales

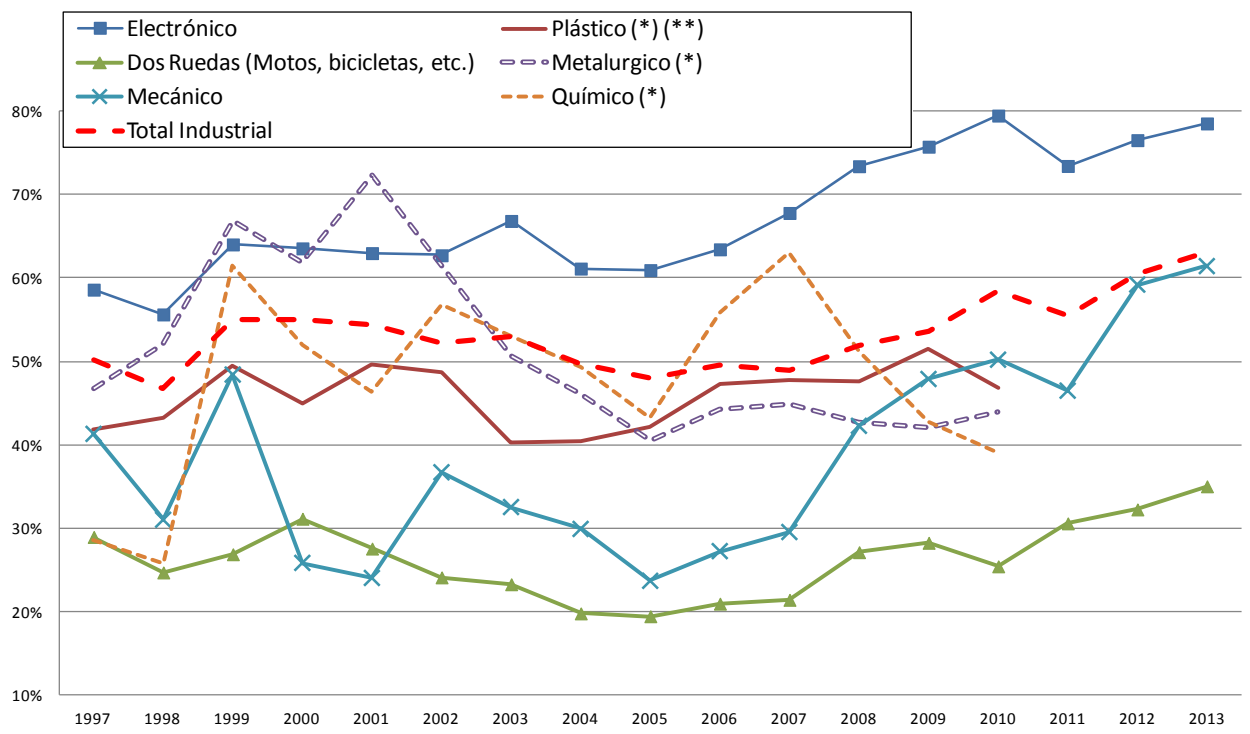

Fuente: Elaboración propia en base a Suframa.

(*) nota: Datos disponibles hasta el año 2010.

(**) incluye encendedores bolígrafos y máquinas de afeitar.

\subsection{Análisis económico comparativo entre el Área Aduanera Especial de Tierra del Fuego y de la Zona Franca de Manaos}

A nivel general, podemos apreciar en el Gráfico 8 que la ZFM posee una mayor escala que TDF en términos de comercio exterior y empleo, tanto a nivel absoluto (zona contra zona) como por firma, puesto que a pesar de que en la ZFM se localizan el doble de firmas industriales que en TDF, la relación en empleo es mucho

(10) Moto Honda de Amazonia es una empresa de envergadura a nivel de la zona, ya que fue la tercera contribuyente en términos del impuesto ICMS del Estado de Amazonas para 2009 (acaparando el 4\% del mismo), luego de Petrobras (20\%) y Samsung (4.7\%). En el mismo rubro, Yamaha Motor de Amazonia se presenta dentro de los principales contribuyentes de este tributo, en el puesto $14^{\circ}$ con el $1 \%$ del total (Da Costa Oliveira, 2011). 
mayor. Asimismo, dicha relación es más elevada aún en los flujos de comercio exterior, especialmente en las exportaciones a terceros países. Por ende, en la ZFM se localizan empresas de mayor escala, y especialmente de mayor inserción externa, con mejor desempeño relativo en las ventas al exterior.

Gráfico 8

Relación Polo Industrial Manaos / Tierra del Fuego para distintas variables

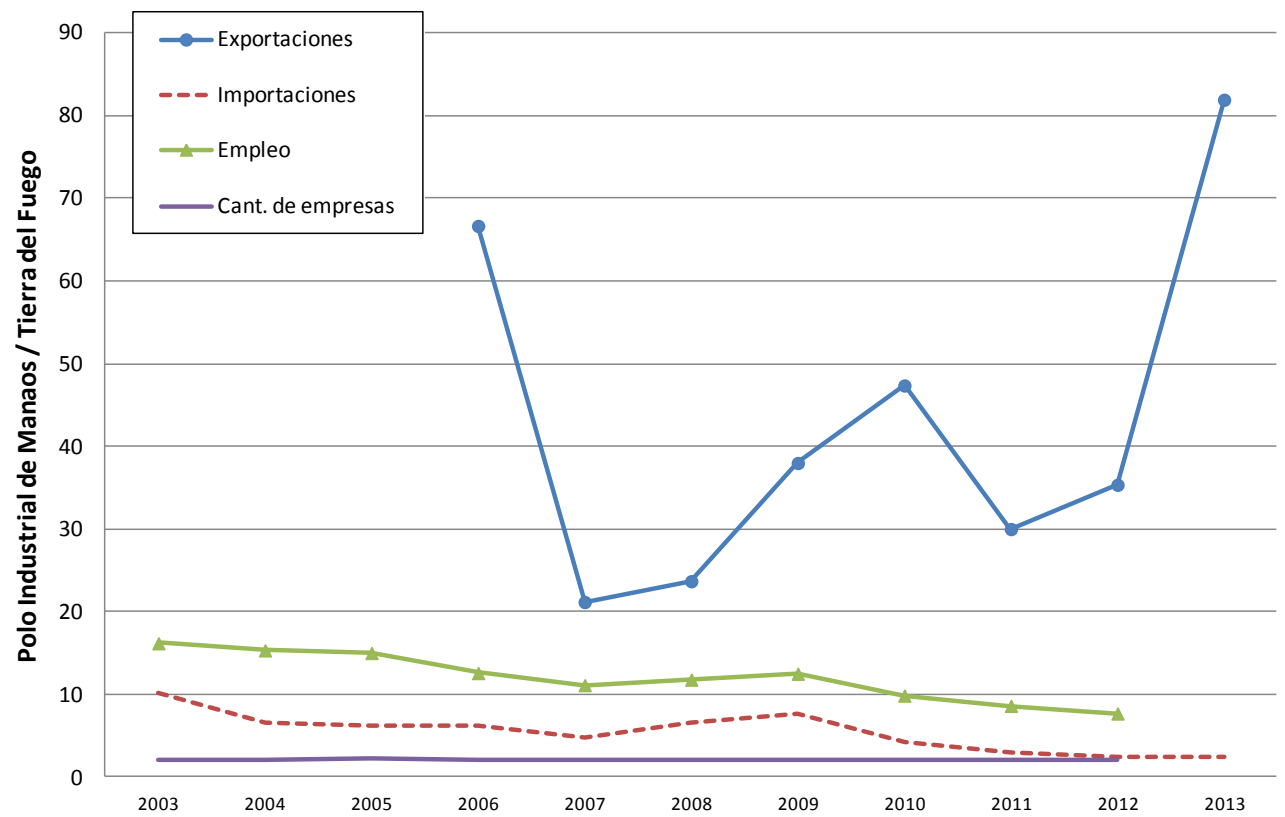

Fuente: Elaboración propia en base a Suframa, Aduana, CEP y Ministerio de Economía de Tierra del Fuego.

$\mathrm{Al}$ analizar el valor agregado bruto (VAB) por trabajador en ambas regiones (Gráfico 9), podemos apreciar que la productividad es significativamente mayor en la ZFM. El VAB por trabajador de la ZFM es creciente durante toda la década, en un contexto de crecimiento de la producción y el empleo industrial de la zona. En cambio, el VAB por trabajador en TDF cae lentamente entre 2003 y 2007, asimismo en un contexto de crecimiento de la producción y empleo industrial. De esta forma, vemos una evolución contrapuesta entre ambas regiones: los procesos de crecimiento y generación de empleo se dan en un contexto de aumento de la productividad en la ZFM, y de incidencia relativamente estable de las importaciones en la oferta total de bienes regionales (ver Gráfico A.3 del Anexo); mientras que dichos procesos en TDF se dan en el marco de una caída de la producto medio por trabajador, y de aumento de la incidencia de las importaciones en la oferta de bienes a nivel regional.

La falta de disponibilidad de estadísticas no permite comparar inmediatamente la composición sectorial del VBP o el VAB industrial en ambas regiones. Sin embargo, podemos realizar una aproximación a dicha composición a través del empleo sectorial. Como se aprecia en el 
Análisis comparativo de la Zona Franca de Manaos y el área aduanera especial de Tierra del Fuego

Gráfico 10, la industria plástica ha pasado a ser relativamente más importante en la ZFM, al poseer 15 empleados por cada empleo sectorial en TDF para el año 2013, superando dicha relación para el total industrial.

\section{Gráfico 9}

Tierra del Fuego y Polo Industrial de Manaos: Valor Agregado Bruto por trabajador registrado industrial

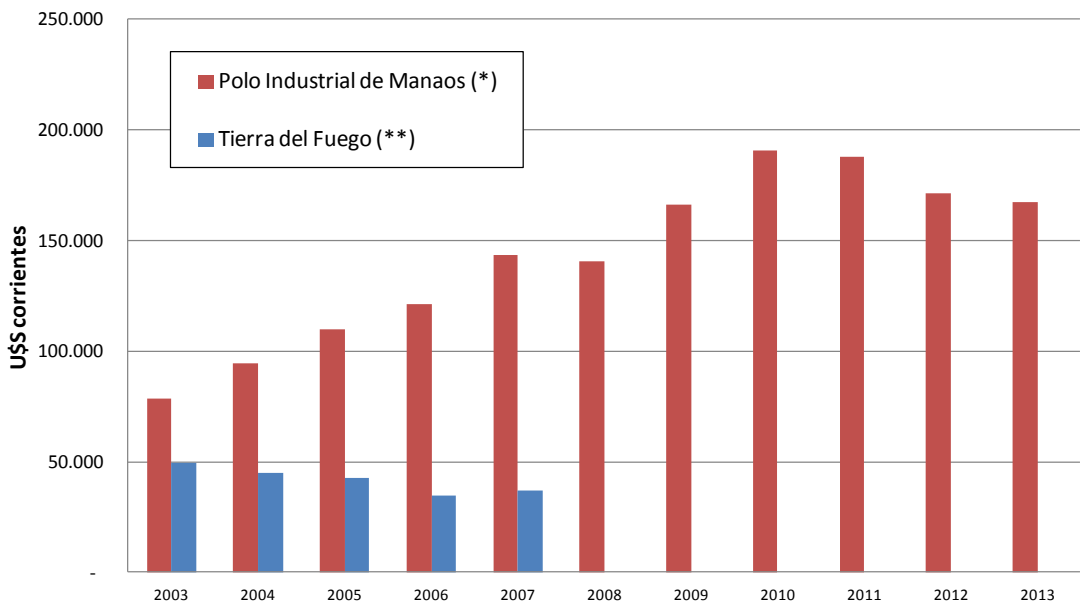

Fuente: Elaboración propia en base a CEP, BCRA y Suframa.

(*) Nota: El VAB industrial está calculado como el VBP descontandole la adquisición de insumos.

(**) Nota: Datos disponibles hasta el año 2007.

Gráfico 10

Tierra del Fuego y Polo Industrial Manaos: relación en el empleo por sector

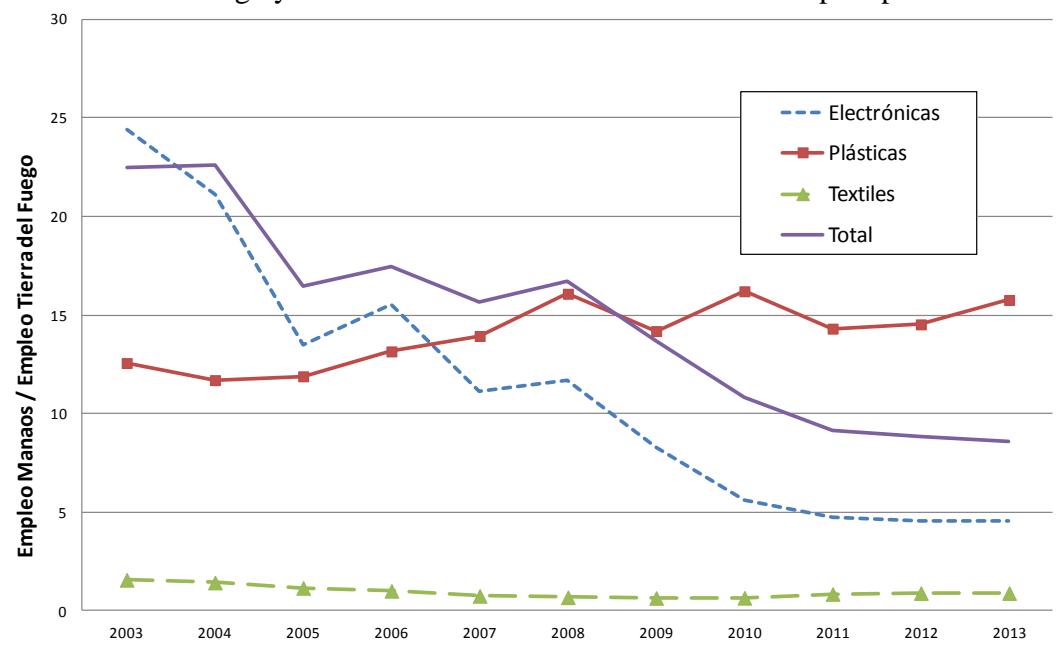

Fuente: Elaboración propia en base a Suframa y Min. De Economia de Tierra del Fuego.

(*) Nota: Los valores para Tierra del Fuego corresponden al empleo sectorial a diciembre del año correspondiente. 
Por otro lado, la industria electrónica posee una relación inferior a dicho promedio, lo que implica que es relativamente más importante en TDF. Por último, la industria textil posee una relación de empleo muy por debajo del total, lo que demuestra su excesiva importancia relativa en TDF en comparación con su incidencia en el empleo de la ZFM.

Es interesante apreciar que, a pesar de las diferencias de escala, ambas regiones poseen un desempeño similar en términos de la participación de las exportaciones en sus ventas totales (Gráfico 11). Mientras que para 2003 la ZFM exportaba cerca del $12 \%$ de sus ventas externas totales (donde el restante $88 \%$ iba al territorio nacional), TDF solo exportaba a terceros mercados un 5\% de sus ventas externas. Para el 2013, dichas cifras se habían reducido a $2 \%$ y $1 \%$ respectivamente, ante el fuerte crecimiento de las ventas orientado a sus respectivos territorios nacionales y el estancamiento de las exportaciones a terceros mercados.

Gráfico 11

Tierra del Fuego y Polo Industrial de Manaos: Evolución de las ventas externas totales (*) y participación de las exportaciones en dichas ventas

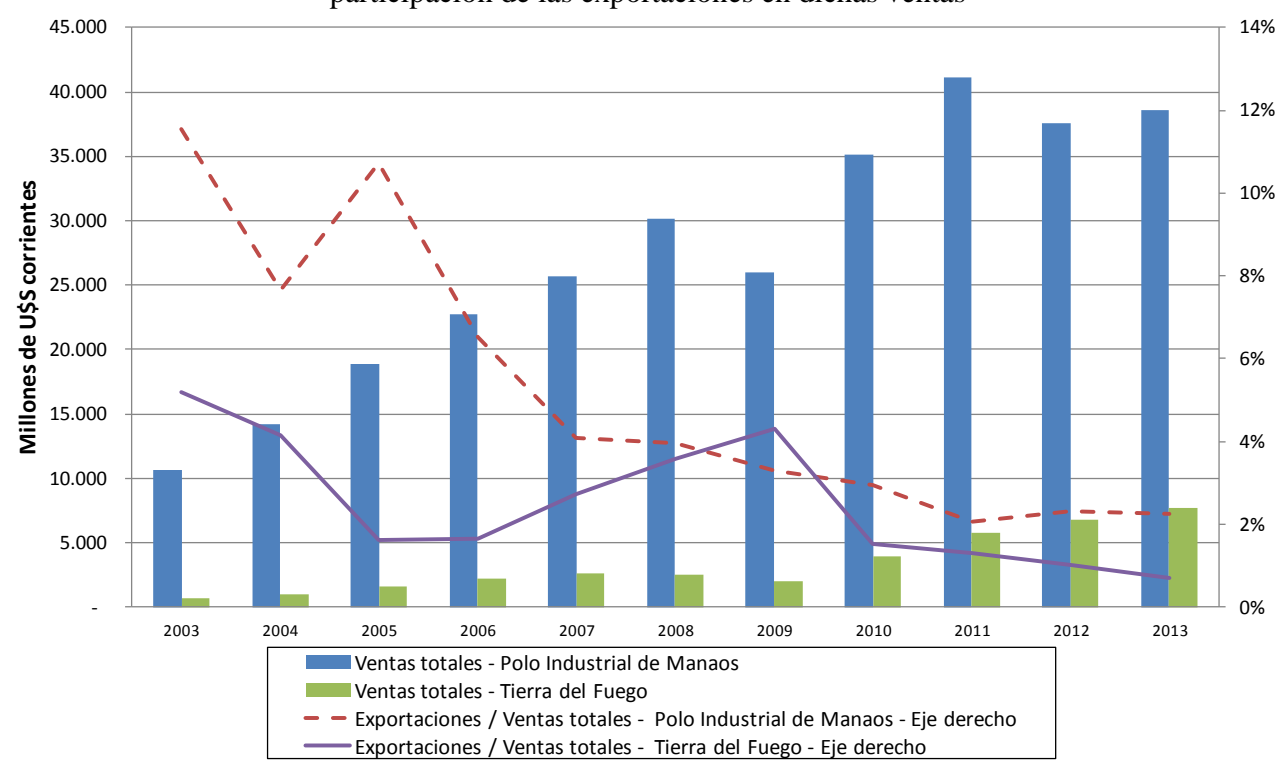

Fuente: Elaboración propia en base a Suframa y Aduana.

(*) Nota: Las ventas externas de cada región incluyen las ventas a su respectivo territorio nacional y las exportaciones a terceros mercados.

Por el lado de las compras (Gráfico 12), nuevamente podemos ver dos fases crecientes, pero diferenciadas cronológicamente: las compras de la ZFM crecen durante toda la década bajo análisis, con excepción en la crisis internacional del 2009; mientras que las de TDF aumentan a partir de los cambios regulatorios del 2010. Sin embargo, la principal diferencia es que mientras que en la ZFM la participación de los proveedores externos en el total es estable, oscilando en torno al $50 \%$ y con un leve incremento hacia fines de la década bajo análisis hasta alcanzar 
el 63\% para el año 2013 (en el marco de apreciación real de la moneda, como destaca Bresser-Pereira, 2015); en TDF dicha participación es mucho más elevada, rondando el $85 \%$ para mediados de la década, y aumentando a cerca del $95 \%$ luego de los cambios regulatorios del 2010. Nuevamente, se remarca aquí una de las principales diferencias entre ambas regiones: mientras que la ZFM ha logrado desarrollar proveedores al interior del territorio de Brasil, la participación de los proveedores argentinos en TDF es prácticamente marginal, y en insumos de escasa complejidad técnica, como ya hemos mencionado (ver Tabla 1 ).

Gráfico 12

Tierra del Fuego y Polo Industrial de Manaos: Evolución de las compras externas totales (*) y participación de las importaciones en dichas compras

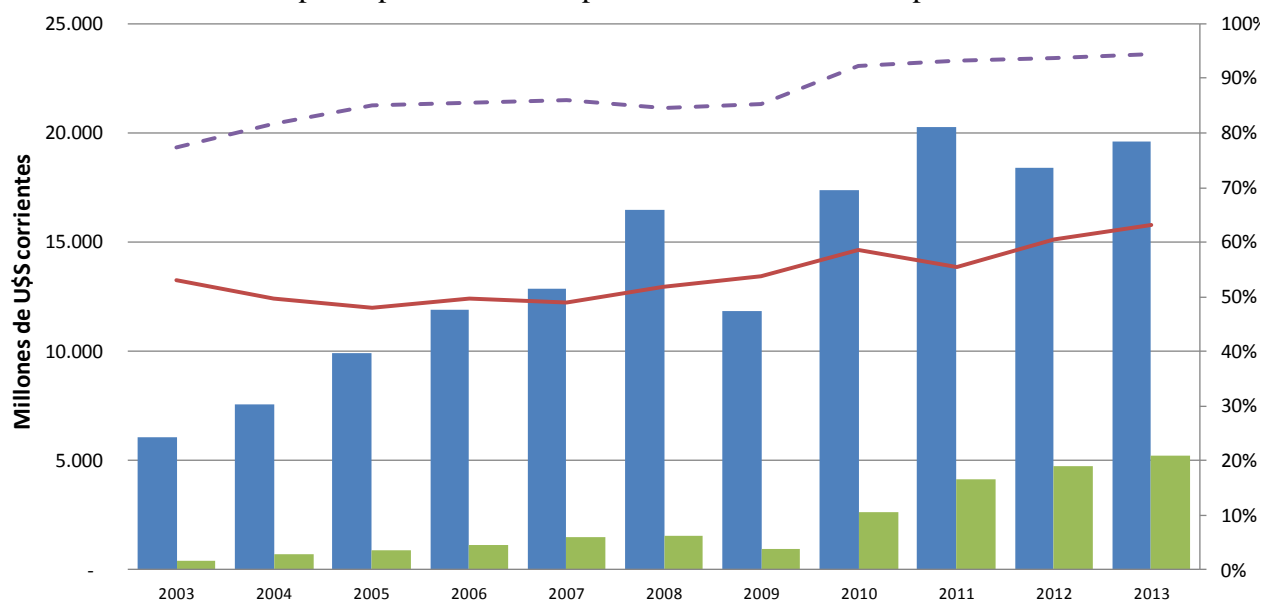

Polo Industrial de Manaos - Compras totales

Tierra del Fuego - Compras totales

_ Polo Industrial de Manaos - Importaciones desde el exterior / Compras totales - eje derecho

- - Tierra del Fuego - Importaciones desde el exterior / Compras totales - eje derecho

Fuente: Elaboración propia en base a Suframa y Aduana.

(*) Nota: Las compras externas contemplan las importaciones y las compras desde los respectivos.

La mayor dependencia de bienes importados por parte de TDF también se aprecia al analizar la incidencia de las importaciones en la oferta agregada a nivel local. El Gráfico A.3 del Anexo muestra que la participación de las importaciones en la oferta agregada de la zona es mucho más importante en TDF (aproximándose al $80 \%$ de la misma para 2007) que en la ZFM (donde dicha relación oscila entre el $30 \%$ y $40 \%$ en la década bajo análisis). De esta forma, la ZFM ha logrado una generación de valor agregado local mayor que TDF, que posee una incidencia relativa de la oferta extranjera en su oferta de bienes mucho mayor.

El efecto de la relativamente mayor integración productiva de la ZFM se corrobora al analizar las importaciones por trabajador del sector industrial (Gráfico 13). Allí podemos apreciar que las importaciones por trabajador de la ZFM fueron estables en la década del dos mil, en el orden de U\$S 50.000 - U\$S 75.000 anuales, con un significativo incremento a partir de 2010 hasta rondar los U\$S 100.000 
aproximadamente. Esto podría estar determinado por el marco de políticas macroeconómicas de inflation targeting, que generaron una tendencia a una fuerte apreciación nominal y real de la moneda brasileña (Bresser-Pereira, 2015). Sin embargo, las importaciones por trabajador industrial de TDF han sido más elevadas durante toda la década, así como crecientes (con una caída en el 2009 por el efecto de la crisis internacional), y especialmente con un fuerte salto importador en los últimos años, donde se motorizaron proyectos relativos al sector electrónico, ante los cambios regulatorios ya mencionados. Como resultado, las importaciones por trabajador de TDF duplican a las de la ZFM, corroborándose la mayor incidencia de la oferta local y de su territorio nacional en esta última zona.

Gráfico 13

Tierra del Fuego y Polo Industrial de Manaos: Importaciones por trabajador del sector industrial

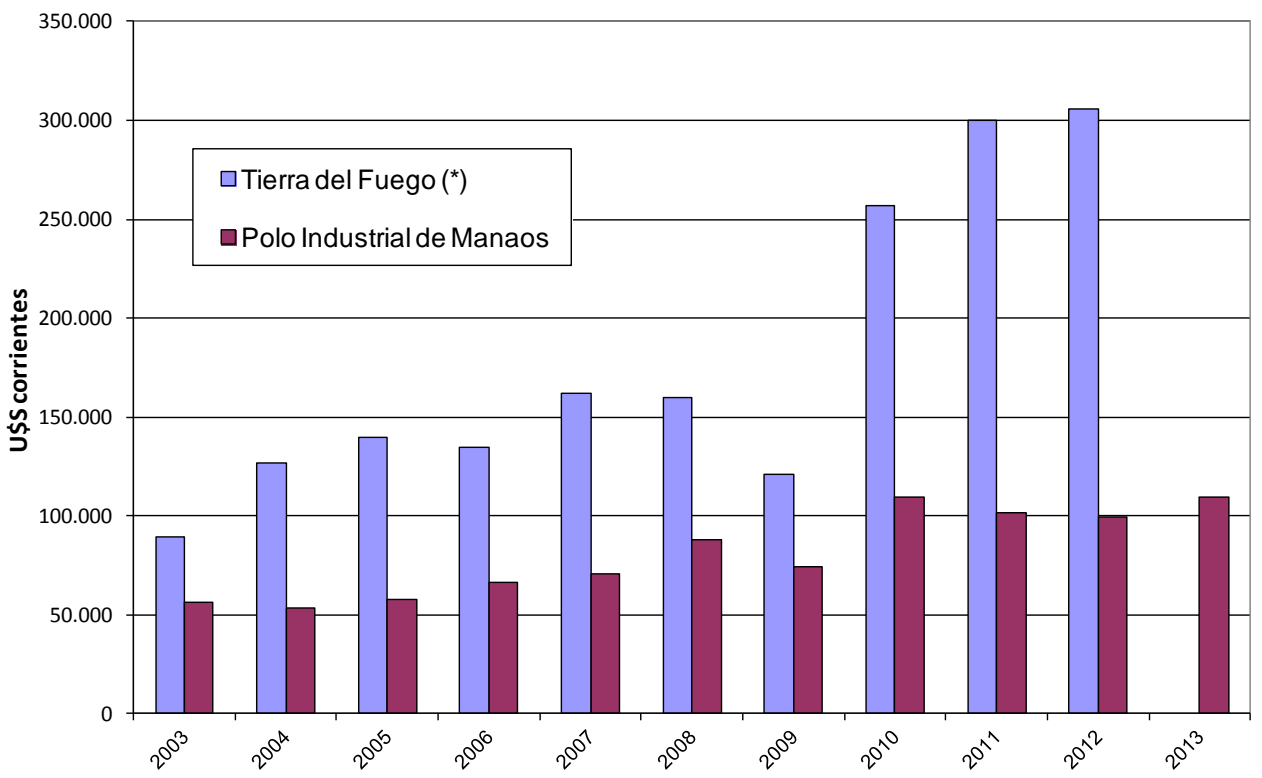

Fuente: Elaboración propia en base a Aduana, CEP y Suframa.

(*) Nota: Datos disponibles hasta el año 2012.

Las exportaciones por trabajador industrial de ambas regiones (Gráfico 14) muestran asimismo un mejor desempeño exportador de la ZFM, a pesar del deterioro ocurrido en los últimos años de la década en dicha zona en el marco de apreciación real de la moneda mencionado (Bresser-Pereira, 2015). Las exportaciones por trabajador de TDF han crecido hacia fines de los dos mil, achicándose la brecha entre ambas regiones en términos de esta variable; pero luego han retrocedido significativamente. Por ende, el desempeño exportador de la ZFM es relativamente mejor que el de TDF, pero dicho desempeño es mucho más significativo en términos de integración productiva local y con su territorio nacional, como se ha apreciado con anterioridad. 
Gráfico 14

Tierra del Fuego y Polo Industrial de Manaos: Exportaciones por trabajador del sector industrial

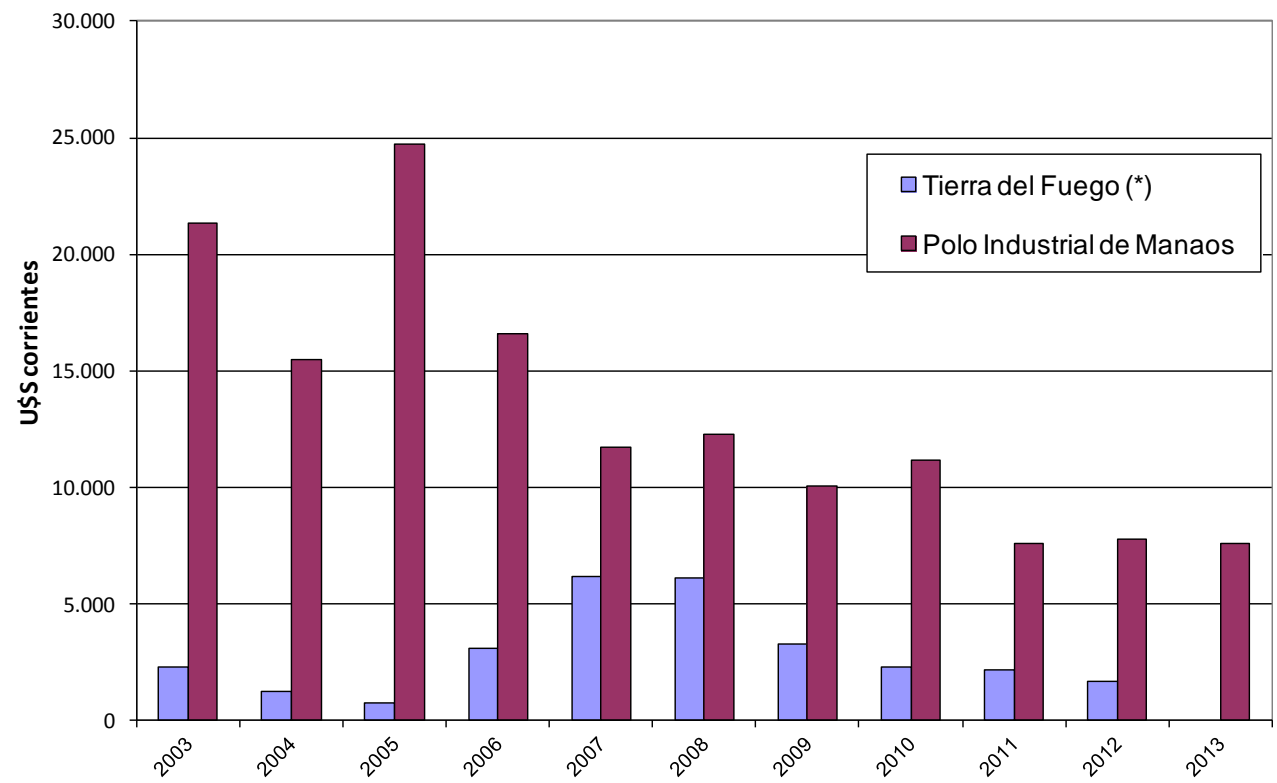

Fuente: Elaboración propia en base a Aduana, CEP y Suframa.

(*) Nota: Datos disponibles hasta el año 2012.

En consecuencia, podemos concluir que el déficit comercial por trabajador de TDF es claramente superior al de la ZFM, y ha crecido fuertemente en el período 2010-2012. Asimismo, es importante remarcar que ambas regiones son fuertemente deficitarias, y que los niveles y evolución de dicho déficit están determinados por las importaciones, debido a que las exportaciones son poco significativas en relación a las compras en el exterior: para TDF en 2012, las importaciones por trabajador superaban levemente los U\$S 300.000, mientras que las exportaciones por trabajador no llegaban a los U\$S 2.000. Para el caso de la ZFM, dichas cifras son de U\$S 100.000 y U\$S 8.000, respectivamente; lo que demuestra la fuerte incidencia de las importaciones en el nivel y evolución del déficit comercial por trabajador.

Al profundizar el análisis a nivel sectorial, el desempeño comercial comparativo de ambas regiones también es heterogéneo. La industria electrónica, por lejos la de mayor incidencia en TDF, es la que presenta los menores niveles de integración en ambas zonas. En el Gráfico 15 podemos apreciar que en este sector el déficit por trabajador de TDF ha sido mayor que el de la ZFM en el primer lustro de la década del dos mil, pero con una tendencia a una reducción de la brecha ante el incremento del déficit en la región brasileña. La reactivación del sector a partir de 2010 en TDF aumentó nuevamente esa brecha, ante el significativo salto de las importaciones por trabajador del sector. En dicho año también aumenta el déficit en la ZFM; pero en niveles mucho menores a los de TDF. Asimismo, el desempeño exportador del sector en Brasil es levemente mejor al argentino en la década de los 
dos mil (expresado en la mayor diferencia entre las importaciones por trabajador y el déficit comercial por trabajador), pero muy poco significativo en relación a las importaciones. A partir del 2010, en el marco de apreciación real mencionado, aumentan las importaciones por trabajador en la ZFM y se reduce la brecha con el déficit comercial por trabajador, lo que demuestra una caída en las exportaciones por trabajador del sector.

\section{Gráfico 15}

Tierra del Fuego y Polo Industrial de Manaos: importaciones y déficit comercial por trabajador del sector electrónico

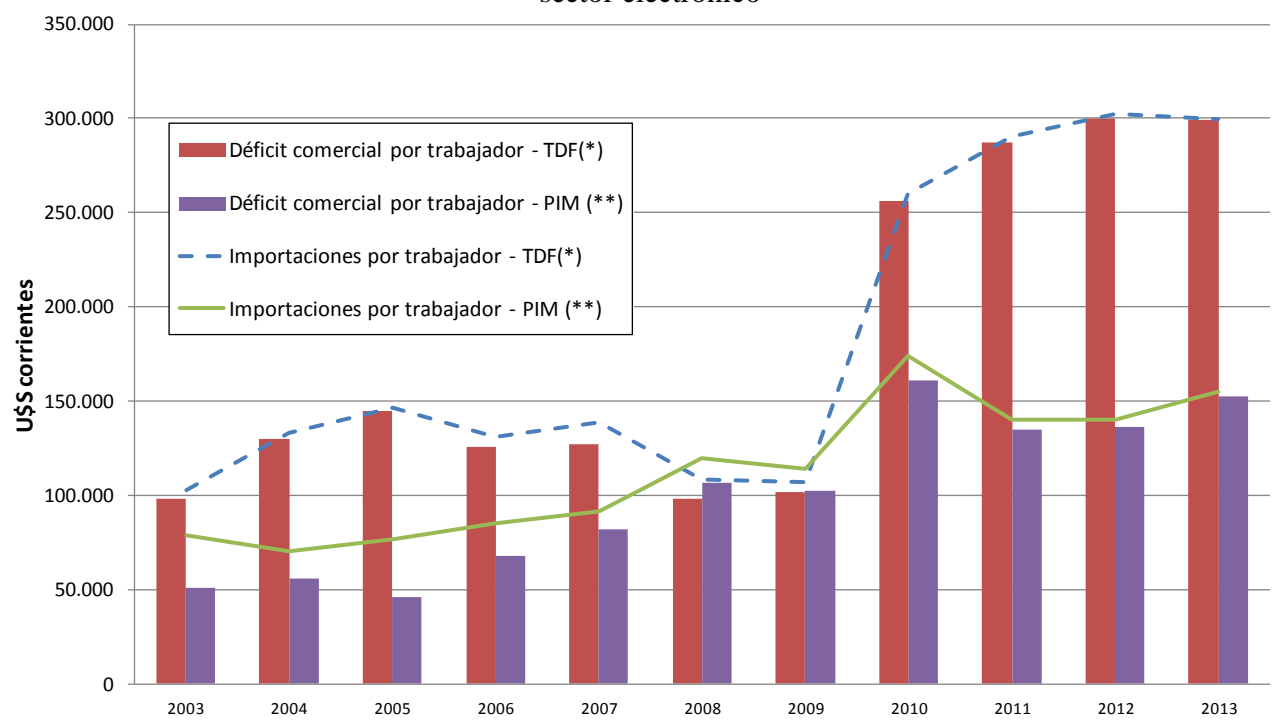

Fuente: Elaboración propia en base a Aduana, Suframa y Min. de Economía de Tierra del Fuego. (*) Nota: El sector electrónico a nivel comercio exterior incluye las partidas pertenecientes a las actividades 30, 31, 32 y 33 de la CIIU Rev. 3 de Naciones Unidas.

** Nota: Las importaciones constan de la adquisión de insumos en el exterior por parte del sector.

Al analizar la integración productiva y los valores unitarios de exportación de celulares y televisores color en ambas regiones (Tabla 2), se aprecia nuevamente la menor integración local de la producción de TDF en relación con la de la ZFM. En celulares, mientras se importa en determinados insumos ${ }^{11}$ U\$S 91 dólares por celular para 2008-2010 en TDF, ese valor se reducía a cerca de U\$S 15 por celular para la ZFM. Sin embargo, la relación se equipara para televisores color: TDF

(11) Es importante remarcar que este conjunto de insumos no es necesariamente la totalidad de los insumos importados. Sin embargo, se han considerado los mismos insumos en las dos regiones, por lo que la comparación es representativa de parte de la integración o desintegración productiva. Asimismo, la existencia de "líneas bolsa" del nomenclador como insumos de ambos productos (donde se nominan todo el resto de los bienes no considerados en las restantes líneas de ese subgrupo del nomenclador), puede sesgar levemente los resultados, al considerar a algunos productos que no se destinen necesariamente a la producción de celulares o televisores color. Sin embargo, por la incidencia de estos productos en los respectivos mix de producción regionales (especialmente en relación con las otras alternativas), dicha incidencia se estima que debe ser poco significativa. 
importa U\$S 138 en determinados insumos por televisor, mientras que la ZFM importa en dichos insumos unos U\$S 148 por unidad de producto. No obstante, la ZFM exporta a terceros mercados a un precio significativamente menor al que TDF vende al territorio nacional argentino, diferencia que se aprecia asimismo en celulares, solo que en dicho caso el mayor precio relativo de los celulares de TDF está determinado en parte por la elevada intensidad de insumos importados: a los precios que exporta la ZFM, la industria de celulares de TDF no podría cubrir los costos de los insumos importados. Es importante remarcar asimismo que ambas regiones, y especialmente TDF, están por encima de los precios promedio de importación en un mercado de referencia como el del puerto de Santos (donde se realizan los intercambios relativos a la región de San Pablo). En este sentido, para el caso de TDF, se aprecia la existencia de altos precios hipotéticamente resultantes de que el territorio nacional sea, en parte, un "mercado cautivo" 12 de los productores locales; donde discernir si dichos precios se transforman en ganancia extraordinaria requeriría un estudio específico sobre los costos del sector.

Tabla 2

Tierra del Fuego y Manaos: Producción, importaciones de insumos, y ventas externas de teléfonos celulares y televisores color

\begin{tabular}{|c|c|c|c|c|c|c|c|c|c|c|}
\hline \multirow[b]{3}{*}{ Región } & \multicolumn{5}{|c|}{ Telefonos celulares (1) } & \multicolumn{5}{|c|}{ Televisores color (2) } \\
\hline & \multirow[b]{2}{*}{ Producción } & \multirow[b]{2}{*}{$\begin{array}{c}\text { Importaciones } \\
\text { de insumos } \\
\text { (U\$S) por } \\
\text { unidad }\end{array}$} & \multicolumn{3}{|c|}{ Exportaciones o Ventas al TN (3) } & \multirow[b]{2}{*}{ Producción } & \multirow[b]{2}{*}{$\begin{array}{c}\text { Importaciones } \\
\text { de insumos } \\
\text { (U\$S) por } \\
\text { unidad }\end{array}$} & \multicolumn{3}{|c|}{ Exportaciones o Ventas al TN (3) } \\
\hline & & & Cantidad & $\begin{array}{c}\text { Valor } \\
\text { Unitario } \\
\text { (U\$S) }\end{array}$ & \begin{tabular}{|c|} 
Valor \\
Unitario / \\
Insumos \\
importados \\
\end{tabular} & & & Cantidad & $\begin{array}{c}\text { Valor } \\
\text { Unitario } \\
\text { (U\$S) }\end{array}$ & $\begin{array}{c}\text { Valor } \\
\text { Unitario / } \\
\text { Insumos } \\
\text { importados }\end{array}$ \\
\hline Manaos (4) & 19.570.336 & 14,86 & 2.409 .777 & 70,23 & 4,73 & 10.697 .843 & 147,64 & 131.243 & 234,20 & 1,59 \\
\hline Tierra del Fuego (5) & 1.837 .078 & 91,14 & 1.754 .309 & 131,08 & 1,44 & 1.873 .317 & 137,68 & 1.861 .297 & 341,41 & 2,48 \\
\hline \multirow{3}{*}{$\begin{array}{l}\text { Puerto de Santos - } \\
\text { Brasil }\end{array}$} & & & \multicolumn{2}{|c|}{ Importaciones } & & & & \multicolumn{2}{|c|}{ Importaciones } & \\
\hline & & & Cantidad & $\begin{array}{c}\text { Valor } \\
\text { Unitario } \\
\text { (U\$S) }\end{array}$ & & & & Cantidad & $\begin{array}{c}\text { Valor } \\
\text { Unitario } \\
\text { (U\$S) }\end{array}$ & \\
\hline & & & 105.323 & 50,38 & & & & 28.791 & 143,97 & \\
\hline
\end{tabular}

Fuente: Elaboración propia en base a SUFRAMA, Min. De Economía de Tierra del Fuego, ADUANA, y Ministerio del Desarrollo, Industria y Comercio Exterior de Brasil Notas:

(1) A nivel comercial el producto final es el NCM 85171231; mientras que los insumos considerados son los circuitos electrónicos (NCM 85177010), las antenas (NCM 85177021), y otras partes ("las demás partes", NCM 85177099)

(2) A nivel comercial el producto final es el NCM 85287200; mientras que los insumos considerados son las contempladas en el NCM 85299020 ("las demás partes")

(3) Para el caso de Manaos, las exportaciones son a terceros mercados; mientras que para el caso de Tierra del Fuego, dichas exportaciones son ventas externas al territorio nacional argentino.

(4) Contempla las transacciones comerciales por puerto fluvial y aéreo de Manaos; asi como la producción del Polo Industrial de Manaos.

(3) Contempla las transacciones comerciales registradas por las aduanas de Ushuaia y Rio Grande; así como la producción a nivel provincial.

En términos del costo fiscal que implican los regímenes bajo análisis, los diversos programas de la ZFM tenían previsto representar el $15.3 \%$ de los gastos

(12) Como hipótesis, mercado cautivo generado tanto por barreras formales como informales, estas últimas naturalmente de difícil comprobación. Por otro lado, no hay que perder de vista que puede existir una alta heterogeneidad cualitativa entre los celulares producidos en ambas zonas, lo mismo que para el caso de los televisores color. Sin embargo, es significativo que los resultados van en línea con la menor integración de la producción industrial en TDF; así como con la hipótesis de la existencia de un elevado precio de origen monopólico para TDF, algo que asimismo se presenta para la ZFM, pero en menor medida. 
gubernamentales indirectos de naturaleza tributaria (fundamentado principalmente en diversas exenciones tributarias) para el 2011, por detrás de un programa para Micro y pequeñas empresas, con el 20.1\% (Da Costa Oliveira, 2011). Para el mismo año, las distintas exenciones del régimen de TDF representaron el $78 \%$ del gasto total en promoción económica (Schorr; Porcelli, 2014). En términos del PBI, las exenciones tributarias de TDF representaron el $0.38 \%$ del PBI argentino en 2011; mientras que en dicho año la ZFM tenía previsto acaparar el 0.33\% del PBI de Brasil en exenciones impositivas. A nivel desagregado, las exenciones de tributos a la importación en TDF representó el $0.08 \%$ del PBI en Argentina, mientras que existía una previsión para la ZFM de que acapare solo el 0.04\% del PBI de Brasil. En términos de IPI e IVA, la relación se invierte: las previsiones para 2011 estimaban que las exenciones del IPI en la ZFM (tanto las vinculadas a las operaciones internas como a las de importación) representarían el 0.29\% del PBI de Brasil (0.25\% para las operaciones internas, y $0.04 \%$ para las de importación); mientras que las exenciones del IVA compras e IVA ventas de TDF representaron el $0.18 \%$ del PBI argentino.

Al considerar el fundamento de este comportamiento dispar, la mayor incidencia del IPI en la ZFM y de los derechos de importación en TDF estaría demostrando una de las principales diferencias entre ambas regiones: la mayor generación de valor agregado local e integración con el territorio nacional de la producción de la ZFM, en contraposición a la mayor dependencia importadora de TDF.

\section{Síntesis y conclusiones}

El fundamento original de la implementación de los regímenes económicos especiales bajo estudio fue el de promover el aumento de la población y el empleo en ambas regiones. Al amparo de los regímenes fiscales y aduaneros especiales implementados puede señalarse que en ambas zonas los proyectos fueron efectivos en la realización de dichos objetivos.

Al igual que TDF, la ZFM destina gran parte de su producción al territorio nacional de Brasil, por lo que también presenta un persistente déficit con terceros mercados. Sin embargo, a diferencia de TDF, los proveedores nacionales juegan un rol significativo en la provisión de insumos; a la par que existe una mayor generación de valor agregado a nivel local. Por ende, se pone en tela de juicio la efectividad del régimen de TDF en términos de intensificar la sustitución de importaciones, especialmente considerando la existencia de proveedores potenciales en el territorio nacional.

Otros aspectos que diferencian a ambas zonas se vinculan con la mayor escala que presenta la ZFM en términos de comercio exterior y empleo, tanto a nivel 
absoluto como relativo a la cantidad de empresas. En términos de dinámica económica, los procesos de crecimiento y generación de empleo se dan en un contexto de aumento del producto medio por trabajador y de incidencia relativamente estable de las importaciones en la oferta total en la ZFM. En cambio, en TDF dichos procesos se dan en el marco de una caída de producto por trabajador, y de aumento de la incidencia de las importaciones en la oferta de bienes de la zona.

La relativamente menor diversificación de la producción en TDF (siendo que en la ZFM poseen producciones significativas los sectores de productos plásticos, metalmecánica y "dos ruedas", prácticamente ausentes en TDF) puede estar fundamentada asimismo en el criterio de no competencia del régimen con los sectores existentes en el territorio nacional, condicionamiento que no existe para el caso de ZFM. Esto determinó asimismo menores niveles de inversiones en TDF, pero la característica relativa principal de las mismas ha sido su volatilidad, en relación al crecimiento estable que presentan en la ZFM. Es importante destacar que dicha volatilidad está relacionada con el carácter errático de la apertura de nuevos proyectos en el régimen de TDF, que nuevamente no se presenta para el caso de la ZFM.

Otra diferencia importante se vincula con el peso proporcional que presentan en cada zona los recursos destinados a cada régimen. Como hemos remarcado, la ZFM es uno de los componentes más importantes del gasto en promoción económica de Brasil, pero no llega a acaparar más del $25 \%$ del mismo, mientras que TDF concentra más del $80 \%$ de dicho gasto en Argentina. Complementariamente, cabe destacar que en la ZFM es relativamente más importante el costo fiscal del IPI, mientras que en TDF pesan relativamente más las exenciones a los derechos de importación, lo que se corresponde con la menor integración productiva y generación local de valor agregado de TDF en relación a la ZFM.

Como ya fue señalado, la ZFM presenta un mayor nivel de diversificación y de integración productiva local y con el territorio nacional. Por ende, es importante tomar en cuenta los requisitos establecidos por la SUFRAMA a los efectos de tener acceso a los beneficios promocionales en la ZFM. Estos requieren, además de incrementar la oferta de empleo y conceder beneficios sociales a los trabajadores, incorporar tecnología de productos o procesos (y específicamente reinvertir el 5\% de la facturación en actividades de investigación y desarrollo), obtener niveles crecientes de productividad, reinvertir sus ganancias en la región y atender a los límites anuales de importación establecidos en las resoluciones aprobatorias de cada proyecto. Asimismo, el esquema de exención arancelaria determinado como la devolución de una fracción (elevada, pero no absoluta) de los aranceles pagados por las importaciones de insumos, puede estar generando un incentivo a la integración mayor en la ZFM que el esquema de TDF, donde dicha exención es absoluta. Esto se expresaría en el sector de "dos ruedas", de importante integración y sujeto a una 
exención de aranceles a la importación de insumos en relación a la utilización de insumos y mano de obra nacional. En los bienes informáticos, la dependencia tecnológica del exterior (compartida asimismo por TDF) habría implicado un menor efecto de esta medida en términos de integración productiva con los proveedores nacionales de insumos. Para el caso de TDF, se vuelve importante considerar hasta qué punto los requisitos establecidos para acreditar origen, como los "procesos productivos básicos", son suficientes para generar una verdadera tendencia al desarrollo de valor agregado local.

Como hemos visto, los esquemas de incentivos analizados han logrado expandir el empleo industrial en ambas regiones. Esto permitió el aumento poblacional de las mismas, objetivo primigenio de fundamento geopolítico y de integración económico-social. Sin embargo, dista de estar claro que estas políticas hayan sido las más eficientes para lograrlo, ante los elevados costos fiscales y distorsiones comerciales de los regímenes: para el caso de TDF, por ejemplo, el sector servicios (especialmente el turismo, de importante ventaja absoluta local) posee similares niveles de productividad que el industrial, revelando una significativa capacidad de expansión de la producción y el empleo sin contar con niveles de promoción tan elevados. Complementariamente, cabe destacar la elevada intensidad de trabajo de dicha actividad así como el fuerte arraigo local de las mismas, dos atributos importantes a la hora de considerar el impacto en la demanda de trabajo y aumento poblacional de la región.

Por otro lado, a pesar de la mayor diversificación productiva de la ZFM, es fácil apreciar la superposición de los mismos sectores en ambas zonas (especialmente en productos de electrónica de consumo, predominantes en TDF). Esta falta de especialización, reflejo de limitaciones en la complementariedad productiva entre Argentina y Brasil en el marco del MERCOSUR, podría superarse mediante una cooperación y coordinación de los gobiernos nacionales y locales de ambos países. Este proceso, tan necesario frente coyuntura internacional, permitiría consolidar una mayor escala productiva en ambas áreas (que sería especialmente provechoso para TDF). Sin embargo, requiere de negociaciones muy complejas ante la dificultad de definir sectores beneficiados y perjudicados en ambas zonas, y de valorar beneficios futuros de carácter incierto en contraposición a los costos de ajuste estructural de corto plazo, entre otras dificultades.

El estudio de la evolución histórica de la normativa demuestra que objetivos de política económica general (especialmente la industrialización y sustitución de importaciones) se conjugaron con los objetivos de poblar las regiones. En estos términos, es importante remarcar que, a pesar de que dichos objetivos se hayan cumplido, dista de estar claro que dicha conjugación de objetivos sea la forma más eficiente de realizarlos: el desarrollo sectorial no necesariamente debe localizarse en dichas regiones, y la mejor forma de poblarlas no necesariamente sea mediante 
dichos sectores, como hemos mencionado. Por otro lado, en términos sectoriales, se han logrado avances, especialmente en la sustitución de importaciones (con menor intensidad en el caso de TDF), pero sin consolidar sectores competitivos con capacidad de exportar significativamente ni de poseer una dinámica tecnológica endógena. En este sentido, es importante remarcar que la falta de un esquema efectivo de reducción gradual de los fuertes beneficios otorgados en los regímenes estudiados no permitió suplantar los estímulos que genera la competencia para la modernización tecnológica y la búsqueda de nuevos mercados, lo que vuelve muy vulnerables a los agentes beneficiados ante cambios regulatorios.

Complementariamente, esta dependencia tecnológica de los agentes locales con respecto a las firmas globales que coordinan las cadenas globales de valor limita la capacidad de intensificar la sustitución de importaciones, así como el derrame tecnológico del proceso de industrialización. Esta problemática debe ser considerada a la hora de debatir los objetivos e instrumentos de política de dichos regímenes, ya que haría posible transformar un régimen de objetivos meramente productivos en uno que conjugue la ciencia, tecnología y producción en la búsqueda de innovaciones en forma sistémica, algo planteado parcialmente en la ZFM con la mencionada obligación de invertir en I+D, y ausente en TDF.

Finalizando, la idea no es plantear desandar el camino realizado (con el muy problemático proceso de desempleo "friccional" local que esto pudiera generar); sino aportar al necesario debate que nutra la futura reconsideración y ponderación de los objetivos, y especialmente la consistencia entre herramientas de política económica y científico-tecnológica y objetivos vinculadas al desarrollo local de las áreas analizadas, así como al desarrollo de los sectores estratégicos para el desempeño económico de ambos países. El análisis realizado demuestra el fuerte desafío que representa consolidar procesos de desarrollo local y de transformación estructural, necesarios para cimentar un proceso de crecimiento económico sustentable y una mejor distribución regional del ingreso en ambos países.

\section{Bibliografía consultada}

BALDWIN, R. Trade and industrialisation after globalisation's 2nd unbundling: how building and joining a supply chain are different and why it matters. Cambridge: National Bureau of Economic Research, 2011. p. 1-38. (NBER Working Paper Series, n. 17716).

BARTIK, T. The market failure approach to regional economic development policy. Economic Development Quarterly, v. 4, n. 4, p. 361-370, 1990.

BARTIK, T. Local economic development policies. Kalamazoo, Michigan: Upjohn Institute, ene. 2003. (Staff Working Paper, n. 03-91). 
BLOCK, F; KELLER, M. Where do innovations come from? Transformations in the U.S. economy, 1970-2006. In: BLOCK, F.; KELLER, M. (Ed.). State of Innovation. The U.S. government's role in technology development. Boulder, Colorado: Paradigm Publishers, 2011.

BOND, P. Debates in local economic development policy and practice. Urban Forum, v. 14, n. 2-3, p. 147-164, 2003.

BRESSER-PEREIRA, L. The macroeconomic tripod and the workers' party administrations. In: PEREIRA, Anthony W.; MATTEI, Lauro (Ed.). The Brazilian economy today: towards a new socio-economic model? London: Palgrave/Macmillan, 2015. p. 121-134.

BRUERA, I.; GRANERO, P.; PARYSOW, J. Cuantificación y caracterización del entramado económico-productivo MIPyME de la provincia de Tierra del Fuego, Antártida e Islas del Atlántico Sur. [s.1.]: Ministerio de Industria e Innovación Productiva de la provincia de Tierra del Fuego, Antártida e Islas del Atlántico Sur, 2012.

CEP. El área aduanera especial de Tierra del Fuego y la Zona Franca de Manaos: objetivos comunes, trayectorias divergentes. Buenos Aires: Secretaría de Industria de la Nación, 2001. Mimeografado.

CIMOLI, M.; FERRAZ, J.; PRIMI, A. Science, technology and innovation policies in global open economies: reflections from Latin America and the Caribbean. Universia, Georgetown University, v. 3, n. 1, 2009.

COOKE, P.; GOMEZ URANGA, M.; ETXEBARRIA, G. Regional innovation systems: institutional and organisational dimensions. Research Policy, v. 26, n. 4-5, p. 475-491, 1997.

CORDEN, M. Política comercial y bienestar económico. Madrid: Ediciones ICE, 1978.

DA COSTA OLIVEIRA, J. Zona Franca do Manaus: um estudo sobre a renúncia tributária dos entes federativos e os beneficios socioeconómicos gerados pelo modelo. Dissertação (Mestrado)-Faculdade de Ciencias Económicas da Universidade, Federal de Río Grande do Sul, Porto Alegre, 2011.

ELIZALDE HEVIA, A. Planificación estratégica territorial y políticas públicas para el desarrollo local. Santiago de Chile: Instituto Latinoamericano y del Caribe de Planificación Económica y Social (ILPES) / CEPAL, Feb. 2003. (Serie Gestión Pública, n. 29).

FREEMAN, C. The 'National System of Innovation' in historical perspective. Cambridge Journal of Economics, v. 19, p. 5-24, 1995. 
GEREFFI, G; HUMPHREY, J.; STURGEON, T. The governance of global value chains. Review of International Political Economy, v. 12, n. 1, p. 78-104, Feb. 2005. GOLDBERGER, A. A course in econometrics. Cambridge, Massachusetts: Harvard University Press, 1991.

HELMSING, A. Externalities, learning and governance: new perspectives on local economic development. Development and Change, v. 32, p. 277-308, 2001.

LIOU, K. Local economic development in China and the Unites States: strategies and issues. Comparative Chinese/American Public Administration, Supplement to v. 69, p. S29-S37, Dic. 2009.

LUPPI, D. Plan Argentina innovadora 2020. Componentes electrónicos. Documento de referencia. Buenos Aires: Ministerio de Ciencia, Tecnología e Innovación Productiva, 2013. Disponible en: http://www.argentinainnovadora2020.mincyt.gob.ar/?wpfb_dl=24.

MAZZUCATO, M. The entrepreneurial state. London: Demos, 2011.

MORGAN, K. The learning region: institutions, innovation and regional renewal. Regional Studies, v. 31, p. 491-503, 1997.

OLIVERA, J. H. G. (1970). Teoría económica y desarrollo industrial. In: OLIVERA, J. H. G. Economía clásica actual. Buenos Aires: Ed. Macchi, 1977. p. 63-72.

PORTER, M. Location, competition, and economic development: local clusters in a global economy. Economic Development Quarterly, v. 14, n. 1, p. 15-34. 2000.

RAMÍREZ, C. El área aduanera especial de Tierra del Fuego y la Zona Franca de Manaos y la vigencia del código aduanero Mercosur. Densidades, Buenos Aires, n. 7, 2011 .

RODRIK, D. What's so special about china's exports? Cambridge: NBER, Ene. 2006. (NBER Working Paper Series, n. 11947).

ROGERSON, C. Tourism-led local economic development: the South African experience. Urban Forum, v. 13, n. 1, p. 95-119, 2002.

ROMER, P. The origins of endogenous growth. Journal of Economic Pespectives, v. 8, n. 1. 1994.

ROS, J. La teoría del desarrollo y la economía del crecimiento. México: Fondo de Cultura Económica, 2000.

SCHINELLI, D; VACCA, C. Hacia una transformación económica de la Patagonia Austral: la actividad turística en la nueva dinámica productiva y su impacto en el 
empleo. Revista de Estudios Regionales y Mercado de Trabajo, Universidad Nacional de La Plata, n. 3, p. 211-234, 2007.

SCHORR, M; PORCELLI, L. La industria electrónica de consumo en Tierra del Fuego. Régimen promocional, perfil de especialización y alternativas de desarrollo sectorial en la posconvertibilidad. Buenos Aires: Universidad Nacional de San Martín, 2014. (Documentos de Investigación Social, n. 26).

STIGLITZ, J. Algunas enseñanzas del milagro del Este asiático. Desarrollo Económico, Buenos Aires, n. 147, Oct./Dic. 1997.

TAVARES Lyra, F. Os incentivos fiscais à indústria da Zona Franca de Manaus: uma avaliação. Brasília: Instituto de Pesquisa Econômica Aplicada - Ipea, mayo 1995. (Texto para Discusión, n. 371).

TEECE, D. Reflections on 'profiting from innovation'. Research Policy, n. 35, p. 1131-1146, 2006.

TEECE, D.; AUGIER, M. The foundations of dynamic capabilities. In: TEECE, D. Dynamic capabilities and strategic management. Nueva York: Oxford University Press, 2009. p. 82-112.

WADE, R. What can economics learn from East Asian success? Annals of the American Academy of Political and Social Science, v. 505. The Pacific Region: Challenges to Policy and Theory. p. 68-79. Sept. 1989.

WOLFSON, J.; FRISKEN, F. Local response to the global change: comparing local economic development policies in a regional context. Journal of Urban Affairs, v. 22, n. 4, p. 361-384, 2000. 
Análisis comparativo de la Zona Franca de Manaos y el área aduanera especial de Tierra del Fuego

\section{Anexo estadistico}

\section{Gráfico A.1}

Tierra del Fuego: Producto promedio anual por trabajador de diversos sectores

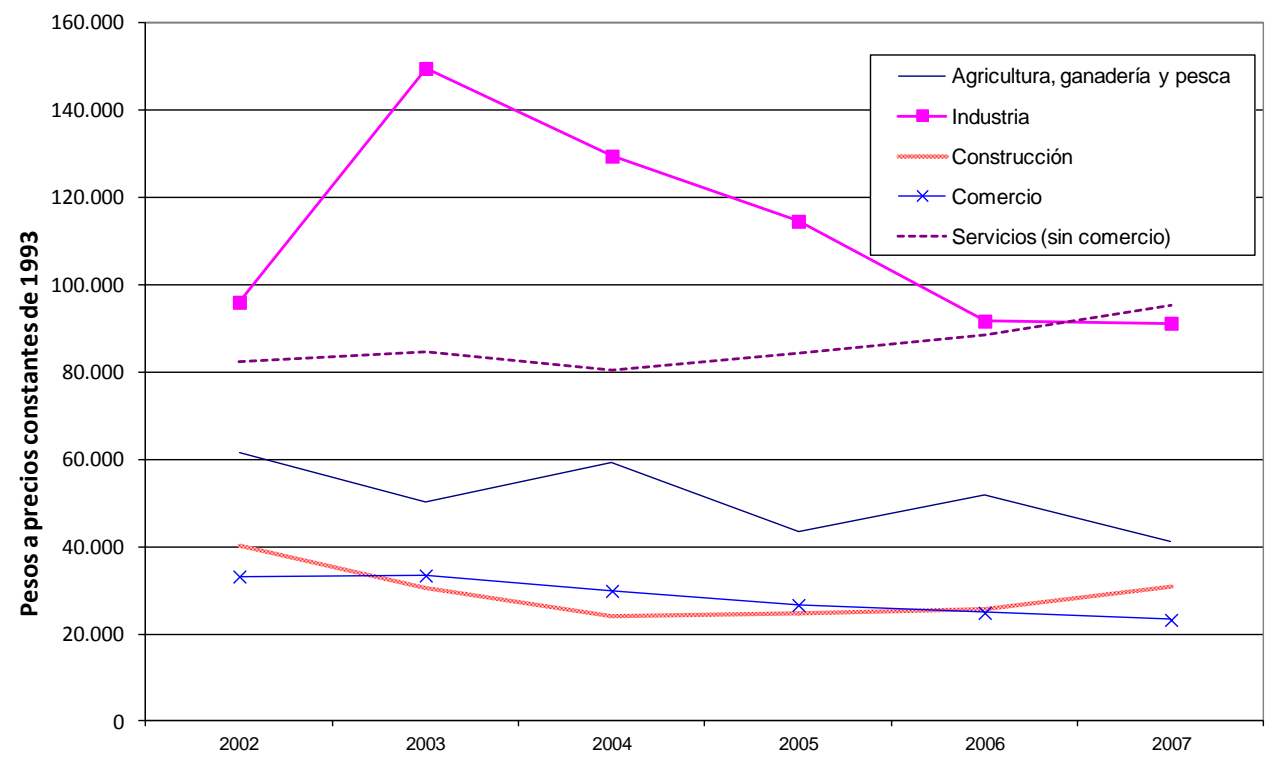

Fuente: Elaboración propia en base al CEP.

Nota: El producto promedio anual por trabajador sectorial ha sido calculado como el Producto Bruto Geográfico del sector dividido por la cantidad de trabajadores registrados del mismo.

Tabla A.1

Tierra del Fuego: Principales productos de importación y exportación

\begin{tabular}{|c|c|c|c|c|c|c|c|c|c|c|}
\hline \multirow[b]{2}{*}{ HS 4 Dig. } & \multirow[b]{2}{*}{ Descripción } & \multicolumn{3}{|c|}{ Exportaciones } & \multicolumn{3}{|c|}{ Importaciones } & \multicolumn{3}{|c|}{ Saldo Comercial } \\
\hline & & \begin{tabular}{|c|} 
Prom. \\
2003-2005 \\
\end{tabular} & \begin{tabular}{|c|} 
Prom. \\
2011-2013 \\
\end{tabular} & Variación & \begin{tabular}{|c|} 
Prom. \\
2003-2005 \\
\end{tabular} & $\begin{array}{c}\text { Prom. } \\
2011-2013\end{array}$ & Variación & \begin{tabular}{|c|c|} 
Prom. \\
$2003-2005$
\end{tabular} & \begin{tabular}{|c|} 
Prom. \\
$2011-2013$ \\
\end{tabular} & \begin{tabular}{|c|}
$\begin{array}{c}\text { Variación } \\
\text { lineal }\end{array}$ \\
\end{tabular} \\
\hline 8517 & $\begin{array}{l}\text { Teléfonos, incluidos los teléfonos móviles (celulares) y los de } \\
\text { otras redes inalámbricas, y similares; y sus partes }\end{array}$ & 0 & & s.d. & 0 & 1.582 & 580691\% & 0 & -1.582 & -1.581 \\
\hline 8529 & Partes para radios, televisores, monitores, y similares & 0 & 0 & $411 \%$ & 67 & 666 & $900 \%$ & -67 & -666 & -599 \\
\hline 8542 & Circuitos electrónicos integrados & 0 & & s.d. & 31 & 198 & $547 \%$ & -31 & -198 & -167 \\
\hline 8415 & Aires acondicionados y sus partes & 0 & 1 & $561251 \%$ & 22 & 187 & $742 \%$ & -22 & -186 & -164 \\
\hline 8414 & Bombas $y$ compresores de aire, $y$ sus partes & 0 & 0 & $-100 \%$ & 31 & 173 & $465 \%$ & -31 & -173 & -143 \\
\hline 8473 & $\begin{array}{l}\text { Partes y accesorios de computadoras, calculadoras, copiadoras y } \\
\text { demás máquinas de oficina }\end{array}$ & 0 & & s.d. & 1 & 114 & $7871 \%$ & -1 & -114 & -113 \\
\hline 9013 & $\begin{array}{l}\text { Dispositivos de cristal líquido; láseres (excepto los diodos láser); } \\
\text { y los demás aparatos e instrumentos de óptica }\end{array}$ & 0 & & s.d. & 4 & 112 & $2959 \%$ & -4 & -112 & -108 \\
\hline 3907 & $\begin{array}{l}\text { Poliacetales, policarbonatos, los demás poliésteres y resinas } \\
\text { epoxi, en formas primarias }\end{array}$ & 0 & & s.d. & 49 & 96 & $98 \%$ & -49 & -96 & -48 \\
\hline 8507 & Acumuladores eléctricos & 0 & & s.d. & 3 & 75 & $2154 \%$ & -3 & -75 & -72 \\
\hline 8504 & Transformadores eléctricos y similares & 0 & & s.d. & 12 & 75 & $514 \%$ & -12 & -75 & -62 \\
\hline 8471 & Computadoras y similares & 0 & & s.d. & 0 & 69 & $25738 \%$ & 0 & -69 & -69 \\
\hline 8518 & $\begin{array}{l}\text { Micrófonos, altavoces (altoparlantes), auriculares, equipos } \\
\text { eléctricos para amplificación de sonido y similares }\end{array}$ & 0 & & s.d. & 3 & 60 & $1670 \%$ & -3 & -60 & -57 \\
\hline 3901 & Polimeros de etileno, en formas primarias & 0 & & s.d. & 6 & 57 & $899 \%$ & -6 & -57 & -51 \\
\hline 8501 & $\begin{array}{l}\text { Motores y generadores, eléctricos (excepto los grupos } \\
\text { electrógenos) }\end{array}$ & 0 & & s.d. & 8 & 49 & $536 \%$ & -8 & -49 & -41 \\
\hline 8544 & $\begin{array}{l}\text { Hilos, cables (incluidos los coaxiales); cables de fibras ópticas y } \\
\text { similares }\end{array}$ & 0 & & s.d. & 4 & 48 & $1009 \%$ & -4 & -48 & -43 \\
\hline 2711 & Gas de petróleo y demás hidrocarburos gaseosos & 20 & 45 & $127 \%$ & 0 & 0 & $-100 \%$ & 20 & 45 & 25 \\
\hline 8527 & Radios, radiograbadoras, radioreloj y similares & 5 & 18 & $258 \%$ & 0 & 0 & $85 \%$ & 5 & 17 & 13 \\
\hline 5101 & Lana sin cardar ni peinar & 1 & 2 & $176 \%$ & 0 & & s.d. & 1 & 2 & \\
\hline 2709 & Aceites crudos de petróleo & 9 & 0 & $-98 \%$ & 0 & & s.d. & 9 & 0 & -9 \\
\hline & Total general & 35 & 66 & $90 \%$ & 552 & 4.416 & $699 \%$ & -518 & -4.350 & -3.832 \\
\hline
\end{tabular}

Fuente: Elaboración propia en base a ADUANA. 
Tabla A.2

Polo Industrial de Manaos: Evolución de la producción de distintos subsectores

\begin{tabular}{|c|c|c|c|c|c|c|c|c|c|}
\hline PRODUCTOS & 2003 & 2004 & 2005 & 2006 & 2007 & 2008 & 2009 & 2010 & $\begin{array}{c}\text { Tasa de } \\
\text { crecimiento } \\
\text { promedio } \\
2003-2010\end{array}$ \\
\hline CONDENSADORES SPLIT & 100 & 25.658 & 47.482 & 52.600 & 74.995 & 215.352 & 357.873 & 509.468 & $152,5 \%$ \\
\hline TELEVISORES LCD & 100 & 78 & 562 & 11.025 & 47.103 & 156.542 & 223.740 & 471.092 & $304,4 \%$ \\
\hline CAMARA FOTOGRÁFICA DIGITAL & 100 & 210 & 380 & 967 & 2.856 & 5.203 & 6.168 & 8.631 & $97,2 \%$ \\
\hline MONITORES INFORMATICOS LCD & 100 & 356 & 1.464 & 5.107 & 13.504 & 9.817 & 4.111 & 5.914 & $76,0 \%$ \\
\hline HOME THEATER & 100 & 382 & 809 & 1.320 & 1.239 & 1.249 & 1.768 & 2.136 & $43,5 \%$ \\
\hline MICROCOMPUTADORAS (INCLUSIVE LAS PORTATILES) & 100 & 203 & 307 & 1.011 & 1.491 & 1.570 & 1.169 & 1.773 & $50,2 \%$ \\
\hline ACONDICIONADORES DE AIRE SPLIT & 100 & 39 & 13 & 12 & 1 & 10 & 388 & 1.083 & $35,0 \%$ \\
\hline PCI - INTERCONEXIÓN DE COMPONENTES PERIFERICOS ( & 100 & 97 & 756 & 859 & 1.017 & 1.308 & 895 & 869 & $39,6 \%$ \\
\hline RECEPTOR-DECODIFICADOR - SEÑAL DIGITAL & 100 & 149 & 186 & 254 & 325 & 442 & 423 & 570 & $27,2 \%$ \\
\hline HORNO A MICROONDAS & 100 & 130 & 169 & 225 & 350 & 324 & 417 & 479 & $25,7 \%$ \\
\hline JUGUETES & 100 & 30 & 14 & 6 & 227 & 389 & 225 & 339 & $46,6 \%$ \\
\hline COMPACT DISC & 100 & 136 & 145 & 164 & 283 & 320 & 381 & 310 & $21,0 \%$ \\
\hline ENCENDEDORES & 100 & 132 & 151 & 153 & 178 & 176 & 176 & 212 & $9,1 \%$ \\
\hline REPRODUCTORES DE AUDIO Y AUTOSTEREOS & 100 & 158 & 184 & 190 & 274 & 300 & 167 & 190 & $8,2 \%$ \\
\hline MOTOCICLETAS & 100 & 110 & 131 & 159 & 197 & 249 & 143 & 189 & $9,9 \%$ \\
\hline RELOJES & 100 & 96 & 105 & 104 & 111 & 129 & 114 & 178 & $6,9 \%$ \\
\hline CAMARA DE VIDEO "CAMCORDER" & 100 & 98 & 84 & 87 & 118 & 152 & 144 & 177 & $10,0 \%$ \\
\hline MAQUINAS DE AFEITAR & 100 & 108 & 114 & 133 & 134 & 142 & 119 & 139 & $4,2 \%$ \\
\hline BOLIGRAFOS Y LAPICERAS & 100 & 92 & 99 & 123 & 94 & 98 & 94 & 120 & $1,3 \%$ \\
\hline TELEFONO CELULAR & 100 & 132 & 202 & 144 & 93 & 114 & 93 & 101 & $-4,5 \%$ \\
\hline RADIOS, GRABADORAS DE SONIDO Y SIMILARES (NO & & & & & & & & & \\
\hline $\begin{array}{l}\text { PORTATILES) } \\
\text { ACONDICIONADORES DE AIRE (PARA VENTANA Y OTROS) }\end{array}$ & $\frac{100}{100}$ & \begin{tabular}{r|r}
158 \\
88
\end{tabular} & $\frac{183}{80}$ & $\frac{106}{77}$ & $\frac{71}{86}$ & $\frac{67}{64}$ & $\frac{50}{60}$ & $\frac{97}{93}$ & $\frac{-10,6 \%}{-3,6 \%}$ \\
\hline $\begin{array}{l}\text { ACONDICIONADORES DE AIRE (PARA VENTANA Y OTROS) } \\
\text { TELEVISORES COLOR (CON TUBO) }\end{array}$ & 100 & \begin{tabular}{c|c|c|}
149 \\
149 & 0 & 0 \\
\end{tabular} & 182 & $\frac{77}{214}$ & $\begin{array}{r}86 \\
176\end{array}$ & $\frac{64}{136}$ & $\frac{60}{84}$ & 93 & $\frac{-3,6 \%}{-8,4 \%}$ \\
\hline VIDEOJUEGOS & 100 & 59 & 55 & 45 & 76 & 61 & 56 & 60 & $-3,6 \%$ \\
\hline BICICLETAS & 100 & 105 & 93 & 66 & 102 & 98 & 51 & 55 & $-8,2 \%$ \\
\hline IMPRESORAS (CHORRO DE TINTA Y SIMILARES) & 100 & 42 & 220 & 76 & 73 & 56 & 5 & 51 & $-21,1 \%$ \\
\hline CAJAS REGISTRADORAS & 100 & 432 & 229 & 257 & 867 & 311 & 150 & 47 & $-9,5 \%$ \\
\hline TELEFONOS (EXCEPTO CELULARES) & 100 & 134 & 137 & 48 & 14 & 17 & 15 & 18 & $-30,6 \%$ \\
\hline $\begin{array}{l}\text { RADIOS, GRABADORAS DE SONIDO Y SIMILARES } \\
\text { (PORTATILES) }\end{array}$ & 100 & 46 & 29 & 9 & 29 & 20 & 12 & 9 & $-24,3 \%$ \\
\hline TUBOS DE IMAGEN PARA TELEVISOR & 100 & 148 & 242 & 229 & 181 & 120 & 40 & 5 & $-30,4 \%$ \\
\hline TUBOS DE IMAGEN PARA MONITORES & 100 & 128 & 133 & 159 & 51 & 12 & 0 & 0 & S.D. \\
\hline FOTOCOPIADORAS & 100 & 105 & 15 & 1 & 0 & 0 & 0 & 0 & S.D. \\
\hline MONITORES PARA SISTEMAS DE SEGURIDAD & 100 & 57 & 43 & 54 & 14 & 17 & 7 & 0 & S.D. \\
\hline MONITORES CON TUBO DE IMAGEN (PARA INFORMÁTICA) & 100 & 101 & 112 & 126 & 39 & 15 & 1 & 0 & S.D. \\
\hline DISQUETES & 100 & 100 & 103 & 107 & 58 & 29 & 6 & 0 & S.D. \\
\hline CASSETTE PARA AUDIO (VIRGEN) & 100 & 63 & 44 & 20 & 1 & 0 & 0 & 0 & S.D. \\
\hline CASSETTE PARA AUDIO (GRABADA) & 100 & 0 & 0 & 0 & 0 & 0 & 0 & 0 & S.D. \\
\hline CASSETTE PARA VIDEO (VIRGEN) & 100 & 115 & 72 & 31 & 3 & 0 & 0 & 0 & S.D. \\
\hline CASSETTE PARA VIDEO (GRABADA) & 100 & 67 & 28 & 2 & 0 & 0 & 0 & 0 & S.D. \\
\hline \multicolumn{10}{|l|}{ Fuente: Elaboración propia en base a SUFRA } \\
\hline Nota № 1: Datos no disponibles para el período 2011-2013. & & & & & & & & & \\
\hline Nota № 2: S.D. = "sin datos" (no se puede calcular la tasa d & imien & & & & & & & & \\
\hline
\end{tabular}


Análisis comparativo de la Zona Franca de Manaos y el área aduanera especial de Tierra del Fuego

Gráfico A.2

Polo Industrial de Manaos: Inversiones por sector industrial

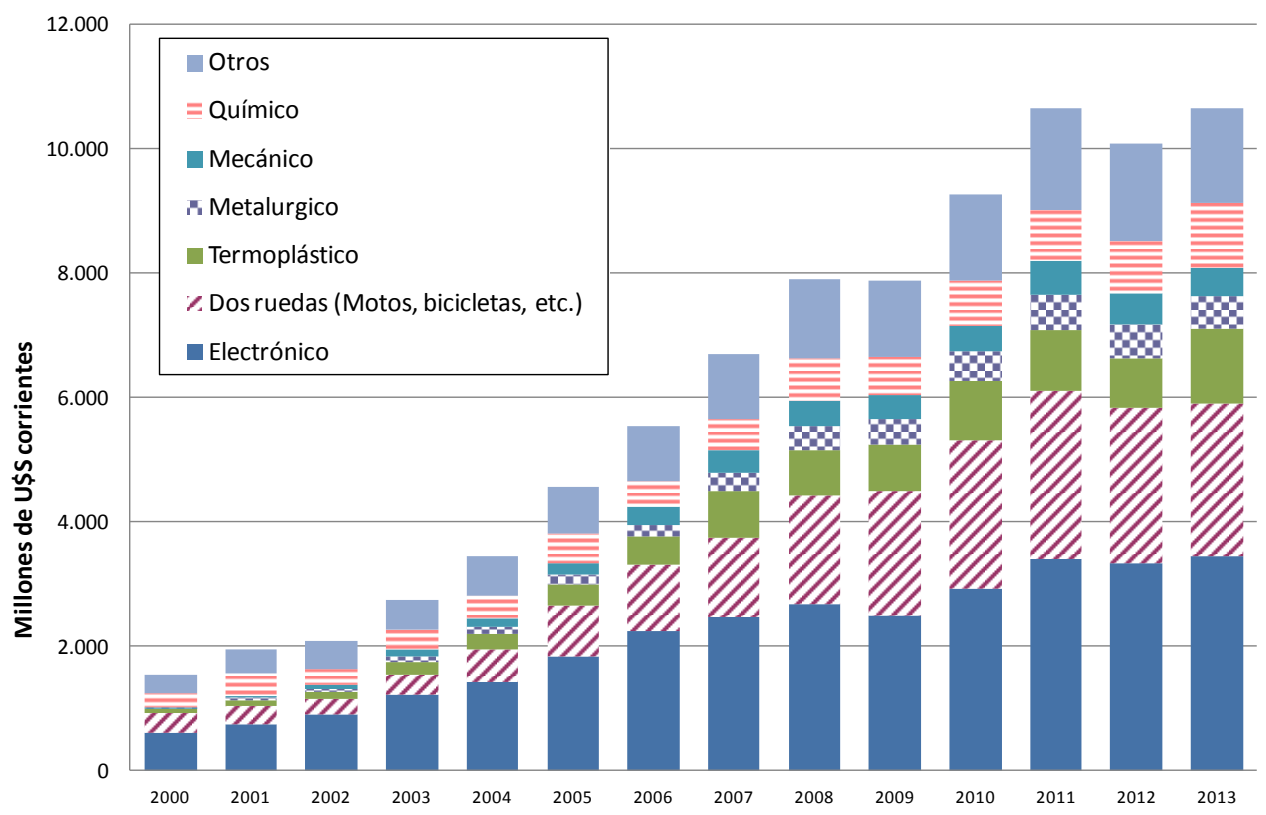

Fuente: Elaboración propia en base a SUFRAMA

Gráfico A.3

Tierra del Fuego y Polo Industrial de Manaos: Participación de las importaciones en la oferta agregada de bienes $(*)$

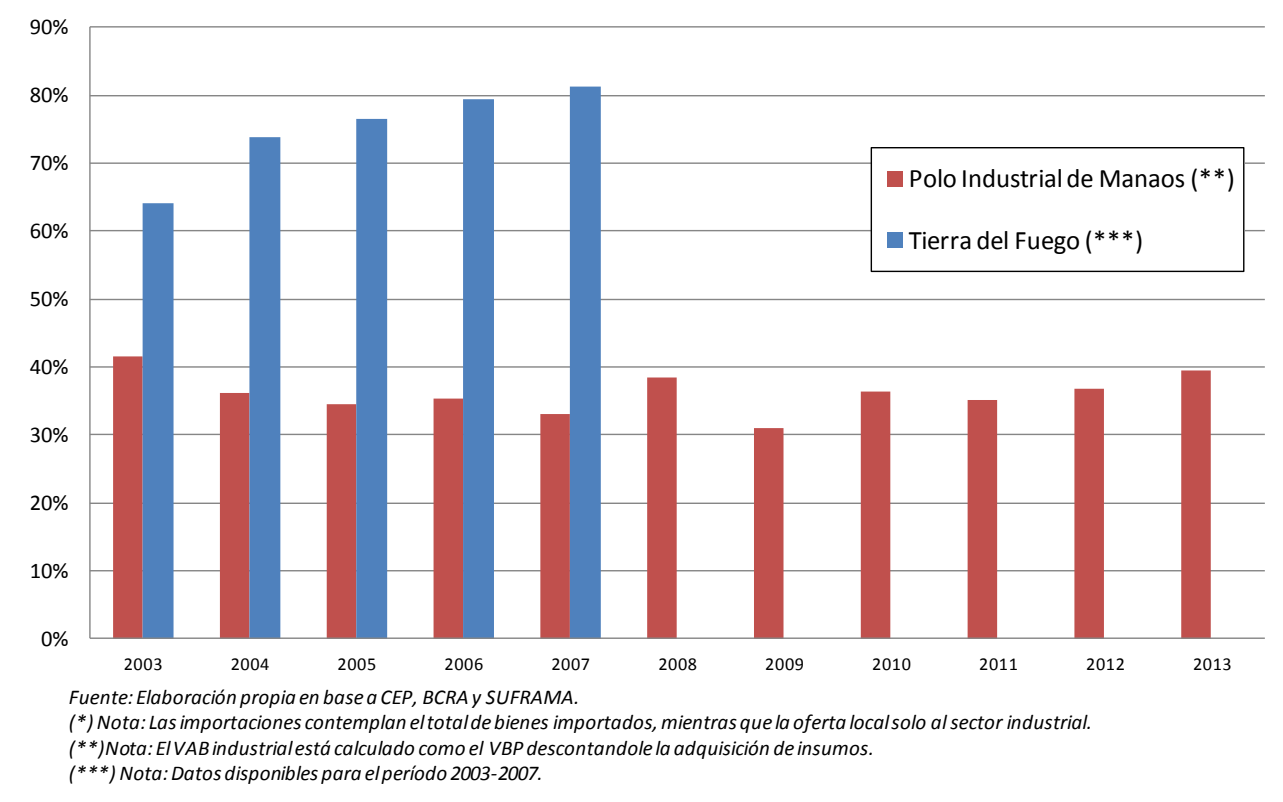

